\title{
Knowledge Management and Experience Transfer in Major Maintenance Activities: A Practitioner's Perspective
}

\author{
Lilian .O. Iheukwumere-Esotu *(D) and Akilu Yunusa-Kaltungo \\ Department of Mechanical, Aerospace and Civil Engineering, University of Manchester, Oxford Road, \\ Manchester M13 9PL, UK; akilu.kaltungo@manchester.ac.uk \\ * Correspondence: lilian.iheukwumereesotu@manchester.ac.uk
}

check for updates

Citation: Iheukwumere-Esotu, L.O.; Yunusa-Kaltungo, A. Knowledge Management and Experience Transfer in Major Maintenance Activities: A Practitioner's Perspective. Sustainability 2022, 14, 52. https://doi.org/10.3390/su14010052

Academic Editor: Roberto Cerchione

Received: 31 October 2021

Accepted: 18 December 2021

Published: 21 December 2021

Publisher's Note: MDPI stays neutral with regard to jurisdictional claims in published maps and institutional affiliations.

Copyright: (c) 2021 by the authors. Licensee MDPI, Basel, Switzerland. This article is an open access article distributed under the terms and conditions of the Creative Commons Attribution (CC BY) license (https:// creativecommons.org/licenses/by/ $4.0 /)$.

\begin{abstract}
Major overhauls, outages, shutdowns and turnarounds (MoOSTs) are significant maintenance interventions needed on a periodic basis to optimise the performance of physical industrial assets (PIAs). However, uncertainties in the forms of emergent and discovery work which sometimes cause delays and cost overruns are quite common partly because, MoOSTs are characterised by inherent challenges such as, but not limited to, short execution spans, volatility in ever-evolving schedules, task complexities as well as huge offline production and/or operation costs etc. Furthermore, in the literature, other complex elements which further constrains decision-makers in MoOSTs from satisfactorily achieving predetermined objectives have been identified, one of which is the lack of a formalised approach for capturing tacit knowledge from experienced practitioners. Consequently, because MoOSTs is an applied discipline, significant human endeavours are required in the planning and management, which makes it pertinent to examine and obtain the perspectives of experienced MoOSTs practitioners. Therefore, the aims of this study are two folds; firstly, to examine the extent of alignment between findings from literature as it relates to the challenges encountered during MoOSTs, as well as probe their underlying causes in practice. Secondly, to show how relevant the findings from this study would be in providing a baseline for establishing a proposal for capturing MoOSTs knowledge and the transfer of experience. The research approach adopted; thematic synthesis of themes which emerged from knowledge management challenges in MoOSTs identified via an earlier systematic literature review (SLR); and then, the identified challenges were validated through conducting interviews with practitioners. Demography analysis as well as specific MoOSTs related questions were administered via questionnaires, which were then analysed using frequency analysis method. Additionally, semi-structured interviews were conducted to investigate the perceptions of practitioners on pertinent MoOSTs issues. Both questionnaires and interview questions were formulated by findings obtained from the SLR, so as to examine whether the knowledge management challenges identified in the literature exist in practice, and if they do to what extent. In total, the selected responses of 49 practitioners, with origin across five industries were examined to determine the extent of alignment between literature and the practice-based perspectives. Based on the results, nine challenges were identified as critical themes, six of which were associated with managing knowledge. The study identified not only known constraints from literature but also their underlying causes based on the perspective of practitioners involved in multiple MoOSTs, which is crucial for developing sustainable mitigation. A unique contribution of this research is the mapping of demographic information such as industry, country, job class, years of experience, MoOSTs organization size, frequency for performing MoOSTs, etc., to responses obtained from participants, which has not been shown in literature prior to now. The importance of such rigorous efforts in the research design, is crucial for enabling the adoption of holistic approaches to eliminating the underlying causes of challenges encountered in MoOSTs, based on first hand reporting of people involved. In addition, the relevance of such first-hand analyses of responses obtained from this study; serve as baseline for the introduction of the proposal to adequately manage knowledge management issues in this discipline.
\end{abstract}

Keywords: knowledge management; experience transfer; maintenance activities; MoOSTs; practitioners perspectives 


\section{Introduction}

The move towards sustainable activities across different sectors has generated increased interests in recent times [1,2]. Large amounts of work towards achieving sustainability have been focused on energy consumption, materials, and environmental considerations $[2,3]$. However, in terms of real-world applications, knowledge management (KM) practices within organisations have shown to be vital in determining how well sustainability targets are met. According to Kordab et al., [4] knowledge management practice and organisational learnings are significant factors to achieve sustainable organisational performance in rapidly changing business environments. In continuous production industries, sustainability is crucial, because physical industrial assets (PIAs) are prone to degradation and eventual failures due to repetitive loads and the harsh environments in which they operate. These failures often result in disruption of production and an inability of organizations to deliver contractual obligations to their clients on time, which might lead to a compromise in budget over-estimation as well as undermine their reputation [5-7]. To reduce the impacts of such disruptions and achieve maintenance efficiency, industrial maintenance activities such as, major overhauls, outages, shutdowns or turnarounds (coined as the acronym MoOSTs here) has emerged as an area of research for both the industry and academia [8]. MoOSTs can be described as an important maintenance management strategy for the total periodic shutdown of plant facilities for a certain time to conduct rare and routine maintenance activities such as inspections, replacements, overhauls, de-rating, renewals and repairs, based on very prudent work packages in order to achieve total asset life cycle optimization $[9,10]$. However, due to continuity features of most industries that perform MoOSTs, shutdown of operations for a definite period is expensive from a planning, execution and logistics point of view. Furthermore, because MoOSTs offers one of the few instances whereby all of the elements of routine as well as complex maintenance tasks are performed at a single instance, it is both capital and labor intensive. It can be easily plagued with delays, cost overruns, as well as uncompleted activities due to brief and strict execution regimes, that are often, associated with reduced margins for errors [11].

Although MoOSTs have attracted the interest of many researchers and practitioners mostly due to its significant impact on plant performance $[6,7,12,13]$, the inability to achieve predicted outcome is still very common. The many challenges associated with planning and management of MoOSTs, are not limited to but include management of uncertainty, resource constraints, unavailability of spares, activity relationships, and organizational behaviors [14]. Traditional project management techniques such as critical path method (CPM), and programme evaluation review technique (PERT) have been used to manage MoOSTs [8]. Unfortunately, delays, cost overrun and uncompleted activities in MoOSTs are commonly observed, thus limiting the effectiveness of applying traditional project management methods alone [6,15].

Hence, it was pertinent to conduct inquiries (empirical studies) to probe persisting issues and provide new perspectives that would shape the directions of future research in MoOSTs. A systematic literature review (SLR) is a useful technique for gap analysis of literature within a research discipline. When conducted properly, SLRs can minimise errors and bias and most importantly leave an audit trial that can be checked by an independent reviewer [16]. Prior to this study, an SLR was conducted by [5] to probe the representation of MoOSTs activities and knowledge trends within MoOSTs management literature as well as identify opportunities for bridging the gaps that currently exist between theory and practice. The SLR identified several classifications, including but not limited to, the origin of research (country related), industry focus, terminologies and research focus. One of the most pertinent SLR finding was the underrepresentation of articles that investigate mechanisms for knowledge management and experience transfer within MoOSTs. The importance of capturing knowledge and expertise during project executions and subsequent transfer within temporary project environments such as MoOSTs cannot be over-emphasized, due to the ratio of tasks-to-duration typically permitted as well as workload uncertainties. Evidence abound that suggests that adopting effective and specific knowledge manage- 
ment and experience transfer attributes related to MoOSTs could improve predetermined outcomes by reducing the occurrence of uncertainty, commonly known as scope creep in traditional project management $[6,9,17]$. Furthermore, the inherent characteristics of temporary project environment creates associated risks of loss of knowledge and critical expertise if not properly captured, formalized, codified and transferred. According to Ruiz et al., [18] it is often easier for people involved in an activity to validate expertise extracted from lived experiences than to directly structure knowledge, which in turn makes management of past knowledge a strategic need for organizations. The importance of effective classification systems for knowledge before subsequent storage cannot be over-emphasised because acceptance of knowledge by the end users after dissemination and future reuse are tied to many knowledge maintenance parameters including, long term applications, relevance, completeness, and accuracy [19].

\subsection{Overview of Knowledge Management (KM) Challenges in MoOSTs}

Despite the wealth of contributions available within existing MoOSTs management literatures, the problem of its effective management and execution persists. This is because despite advances in the development of techniques for predicting deterioration and loss of integrity of critical physical industrial assets (PIAs), there are still associated risks of discovering additional or emergent work, due to reasons such as oversight in determining project work scope, equipment deteriorating faster than predictions made from predictive tools analysis, and/or damages associated with disassembling PIAs for inspections, etc. $[9,20,21]$. A major research challenge that impacts on effective decision-making during MoOSTs is characterised by the need to effectively capture tacit knowledge, in several forms, including lessons learned, technical know-how and general information generated from previous MoOSTs and subsequent reuse [9,22,23]. This is because MoOSTs knowledge is held by collective groups of individuals (experts) and due to the nature of MoOSTs activities, the anticipated loss of knowledge and specialists skills are constant [24]. Furthermore, because MoOSTs activities are periodic, large amounts of information generate large amount of data. Please note that the 'information' referred to here, is experience, technical know-how and insights which comprises of knowledge [25], a KM system that aims to provide complementary solutions for prognosis and enhanced decision-making during the execution of MoOSTs activities is crucial. It is important to emphasise that most organisations are not bereft of data, information and explicit knowledge, rather, the challenge is usually on varying reasons including but not limited to; identifying knowledge sources, as well as effective knowledge maintenance actions that can foster knowledge relevance and reuse $[7,26,27]$.

\subsection{The Importance of Knowledge Management (KM) in MoOSTs}

Knowledge management (KM) facilitates the systematic identification, acquisition, storage/retention, transfer and utilization of knowledge by individuals, teams and entire organizations to reach their strategic and operational goals [28]. KM is not an end in itself, but fundamentally entails capture and reuse which in turn help organizations to prevent failures as well as identify new solutions to problems already faced by the organization [29]. $\mathrm{KM}$ is particularly important for project-based learning, because the systematic identification of knowledge and retention of project experiences enables an organization to compare the performance of its various projects, document its most effective problem-solving mechanisms for future use and gain competitive advantage [28,30]. According to Ambani et al. [6] knowledge is the most valuable asset of an organization, as it enables it to differentiate itself from competitors and to compete efficiently and effectively to the best of its ability.

However, due to the inherent characteristics of MoOSTs the applications of KM in practice could be unattainable due to contrasting elements and objectives. The inherent characteristics of MoOSTs [12,31] that make knowledge management applications challenging including but not limited to, task uncertainties, compressed schedules, dynamic and frequent scope changes; selection of highly experienced practitioners to perform critical 
tasks and many others. Several, research studies have identified the inherent characteristics of MoOSTs as barriers to knowledge management, take for instance heavy workload is a major reason for having limited or no time for knowledge sharing [30,32]. Ambiguity in the content and context of knowledge along with uncertainty, act as barriers to knowledge [33]. Task uncertainty that can arise from factors including, discovery of large amount of unplanned and/or emergent work which can affect identification and distribution of knowledge elements. Consequently, dynamic and frequent scope changes commonly experienced during MoOSTs can create ambiguity in the content and context of knowledge as variables change quickly. In addition, because plant and production activities are shutdown during MoOSTs task execution and handover activities are crucial leaving little or no time for either learning or reflections during or in between cycles. Furthermore, due to the complexity of some maintenance tasks that are performed during MoOSTs, selection of highly experienced staff to perform critical tasks is quite common with the challenge being that only few people are in possession of critical skills as well as expertise. According to Peng [34] when knowledge is centered around an expert it can lead to psychological ownership, that is, the belief of an individual that he/she has ownership rights to the object (knowledge) in question.

\subsection{Knowledge Management Process (KMP) in MoOSTs}

In the literature, knowledge management process (KMP) has in general maintained two major streams of focus in the past, with the first being on knowledge itself, exploring knowledge creation and conversion process in organisations. The second stream of focus takes an approach that investigates activities such as knowledge generation, capture, sharing and utilization to gain competitive advantage [35]. From the second stream of focus, knowledge is only meaningful when it is codified, classified, given a shape, put in a useful format, stored for future use by the right person, at the right time, and in the right way [36]. Much has been written on the importance of managing knowledge processes, that is, about the processes that are used to identify, capture, share and use project-based knowledge, but considerably less has been written on the exact mechanisms for managing this process in MoOSTs [24,35,37]. A review of the literature has identified different elements of KMP, but they can all be distinguished under four key KMP elements, namely, knowledge creation (KC), knowledge transfer (KT), knowledge storage/retrieval (KSR) and knowledge application (KA) [38-40]. KC refers to accumulation of knowledge, in project-based organisations such as MoOSTs, knowledge identification (KI) and KC do not have clear boundaries separating them, and mostly have similar connotations [41]. KT refers to the measures and procedures for transferring and sharing knowledge. According to Bell [24], KT techniques can be broadly categorised as either 'capture' or 'share'. KSR involves the activities of documenting and codifying knowledge that has been identified in the organisation in order to stem loss of knowledge that might arise as a result of factors such as, infrequent use of knowledge, staff retirement and/or departures [41]. KA is concerned with the forms and procedures of applying appropriate knowledge within an organisation to create value both internally and externally [39]. A major consideration for MoOSTs organisations, is the effective integration of the four KMP into their business process to improve organisational learning and performance [42]. Consequently, a major requirement of the KMP is to establish an effective KM system and appropriate technologies to facilitate the four KMP areas.

\subsection{Experience Transfer in MoOSTs}

According to [30] an organization can develop competitive advantage by building capacity to harness the knowledge possessed by its employees. This is because effective knowledge capture requires turning personal knowledge into corporate knowledge that can be shared and properly managed throughout the organization [43]. Personal knowledge possessed by employees are mostly tacit knowledge and employers who leave, take away such valuable knowledge, resources, skills and experiences [41]. The distinction between 
tacit and explicit knowledge is important because it influences the adoption of different transfer techniques for developing effective KM systems. Explicit knowledge can be easily articulated and codified and is expressed in words, numbers, and symbols, which can be shared as theories, principles, specifications, data and others [44]. Conversely, tacit knowledge is difficult to express and/or codify, because it is rooted in the individual's actions and experiences, as well as emotions, and values [44]. Consequently, because it is very easy for knowledge to be lost within organizations, it is of immense benefit to capture tacit knowledge before it is lost through mergers, reorganizations, downsizings and/or culture changes $[43,45]$.

MoOSTs is characterized by large number of staff and contract workers performing large-scale as well as complex maintenance activities at an instance [46]. These workers depend on the organization's explicit knowledge and protocols when dealing with standard issues, in contrast, when dealing with unexpected and/or non-standard problems, they develop work related tacit knowledge [24,47] which include but not limited to, practical know-how, work experience, procedures, as well as skills in specific contexts. While creation and transfer of explicit knowledge are mostly captured in many studies, capture and subsequent transfer of tacit knowledge, in this instance "expertis". is still scant despite its importance to MoOSTs organizations. Since the importance of expertise in MoOSTs has been highlighted, going forward, expertise coordination and knowledge codification would amount to significant contributions to this discipline, because, at present MoOSTs organizations favor a personalization strategy, associated with the routinization of actions and roles as well as sharing of knowledge through personal contacts [48]. However, routinization of actions and roles which is common in MoOSTs because each team member know their jobs and there is no need for anyone else to know anyone else's job since only experts are assigned to specific tasks, as well as sharing of knowledge based on personal relationship, leaves the knowledge holder with too much power. Elements from adopting such personalization strategy has been identified as barriers to knowledge management and experience transfer in MoOSTs [49]. However, organizations can adopt a codification strategy, and make knowledge an organization resource by depersonalizing it. This view of expertise codification significantly reduces the challenges of coordinating expertise by limiting knowledge related dependencies between groups [48].

\subsection{Knowledge Management (KM) in Industry 4.0 and Its Relationship to Employees Competencies in MoOSTs}

Industry 4.0 implies a revolution where industrial processes integrate computer tools to facilitate the handling of large amounts of data and related information, as well as their transfer and interpretation, because previous means for storing information are restrictive for handling large data that are generated due to, the interconnectivity of most organizations global systems [50]. The rapid advancement and development of information and communication technologies (ICT) and integration of maintenance process within these frameworks, means most organizations are facing challenges and at the same time competency needs [51,52]. Such integration, which is called cyber-physical systems (CPS) are systems that can measure and process information up to the level that makes it usable for the end users [53-55]. Hence there is need to rethink new employee competencies that will allow development of a CPS structure capable of implementing big data predictive analytics for transformation of data to information to knowledgeable action such as those advocated by internet of things (IOT), cloud computing, and augmented reality, to improve decision-making $[51,53,56]$. This is because, predictive and prescriptive maintenance of production systems including equipment and physical assets which will be the most important application areas of industrial analytics within the next three years [54]. Thus, there is need for developing knowledge-based decision support systems to improve efficiency and effectiveness of industrial processes [54,57]. KM is a key enabler in this age of rapid technological innovation learning and since man-machine interface is a cornerstone of industry 4.0, it has become even more imperative to answer fundamental questions of 
"who does what, when and under which conditions". [42]. KM in the era of industry 4.0 (KM 4.0) in both human and technology-oriented perspectives is a strategic and operational function, and the revival of artificial intelligence (AI) and emergence of autonomous and learnable technologies challenge the unique role of humans as knowledge actors, decisionmakers, problem solvers and learners [42]. MoOSTs organizations are considered high knowledge-intensive organizations, based on the number of activities they perform and large the amounts of information they possess, but to be successful in the era of industry 4.0, increase in information technology expenditure, developing intranets, data warehousing, and use of internet to create effective and efficient knowledge management practice is key [58]. In literature, three main categories to classify core employee competencies exist namely, technical competencies which comprises of job-related knowledge and skills, for instance in industry 4.0, coding skills, knowledge management, and large information handling, etc. $[59,60]$. Secondly, managerial competencies include all skills for problem solving and decision-making. Thirdly, social competencies, the bedrock upon which expectations for future interactions with others would be built and include skills such as social and interpersonal communication, which are crucial to managing MoOSTs. However, due to the development of new technologies which trigger improvements in existing KM systems and rapid digitalization, identifications of the competencies of future managers and engineers involved in MoOSTs (especially maintenance of complex manufacturing systems, special IT and technologies for managing knowledge, more creativity, strategic thinking, etc.) needs to constantly reassessed [56].

Therefore, the aim of this study is twofold; firstly, to conduct an empirical study across diverse industries involved in MoOSTs activities to obtain the perspectives of practitioners, in order to validate the findings generated from the SLR. This should help determine the extent of alignment between research and practice, as well as probe underlying causes of any alignments or misalignments. Secondly, because there are limited proposals investigating tacit knowledge capture and transfer as a possible mechanism for managing uncertainties in MoOSTs, a new proposal for capturing tacit knowledge and facilitating experience transfer is briefly presented in this study. Thus, the research questions for the empirical study are as follows:

(1) What knowledge management challenges, are identified in real-world practices, during MoOSTs?

(2) To what extent does the knowledge management challenge in the literature identified during MoOSTs align with real-word practice?

(3) Can examination of underlying cause of the knowledge management challenges identified during MoOSTs, foster the development of a proposal for a formalised platform for capture and transfer of tacit knowledge across MoOSTs organisations?

Following the investigation, and exploration of emerging themes, a proposal establishing a platform for formalising tacit knowledge capture in MoOSTs is detailed. It is the belief of the authors that, the unique cross-correlation of theory and practice allows for the identification of strengths, weaknesses and common omissions from both facets (i.e., theory and practice).

This paper is further organized as follows; section two contains details of the research design, pilot investigation, sampling technique and sample size, section three demonstrates the implementation of data analysis methods and results for both surveys and interviews data, Section 4 is discussion of findings, Section 5 is concluding remarks and a brief proposal introduction for a knowledge management platform.

\section{Research Design}

The research design involved two main approaches for data collection, questionnaires [61,62] administered via a web-based platform and semi-structured interviews $[63,64]$ conducted remotely. In total, 49 professionals involved in MoOSTs across five industries based in the UK, USA and Nigeria were respectively recruited. The period for data collection was between February and July 2021. The study investigated pertinent issues relevant 
to the management of MoOSTs. The questionnaires were administered through "Qualitric". (www.qualtrics.manchester.ac.uk; accessed on 14 December 2021), a University of Manchester approved survey platform due to its conformance with global data protection regulations (GDPR). The demographic information of participants such as, qualifications, level of expertise, job class, industry, years of experience, size of organization, staff turnover, and locations were gathered in the first section of the questionnaire. The later section of the questionnaire covered MoOSTs related questions such as, drivers for performing MoOSTs, causes of delays, estimated use of contracted services, MoOSTs frequency, MoOSTs budget, common approaches for documenting lessons learned, approximations of targeted performances of MoOSTs, based on duration and cost objectives [65-68]. Furthermore, during the semi-structured interviews, each participant was asked open ended questions, some of which were earlier presented in the survey as close-ended questions. Some of the questions presented to participants during the semi-structured interviews tried to ascertain commonalities about commonly adopted names for maintenance activities across industries, reasons for delays in MoOSTs, frequency, financial implication of delays, dynamics of maintenance team, mode of communication, and barriers to learning [69-71]. Each participant was aware of the study purpose and gave informed consent. Figure 1 is a flow chart diagram-depicting construct of this study's research methodology.

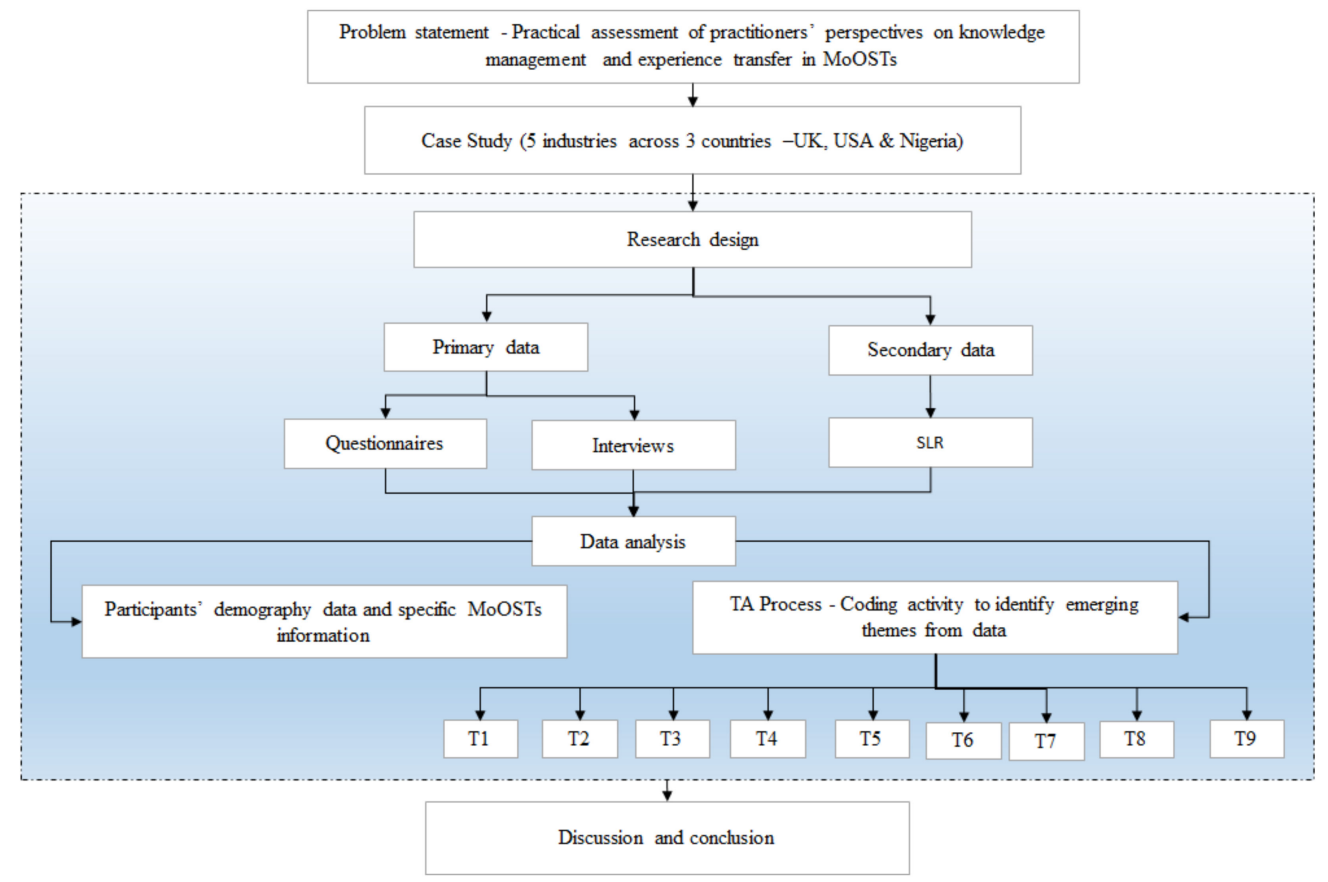

Figure 1. Flow diagram of research design. Note: T1-nomenclature; T2-mode of communication; T3-dynamics of maintenance team; T4-impact of delays; T5-causes of delay and budget overspend; T6 - responsibility for knowledge and experience maintenance management; T7-personal experience of learning; T8 - formalized approaches for knowledge capture and experience transfer and T9-barriers to learning.

\subsection{Pilot Investigation}

To determine the usefulness, duration, representativeness and ease of interpretation of the survey and interview questions, a pilot investigation was initially conducted for calibration purposes. Pilot and feasibility studies have an important role to play in empirical studies because they can provide sufficient methodological evidence about the design, planning and justification of the main study, and can also inform critical elements of the main design to reduce or eliminate problems at later stages of the research [72,73]. Approximately 15 participants, with nine of the participants coming from the manufacturing industry (cement plant) and six participants from the utilities industry (water plant) were recruited 
for the pilot studies. Before the pilot investigation commenced, participants were emailed documents, which explained the study's purpose and content. They were advised that they could withdraw from the study at any time and reassured that none of their identifiable personal details would be shared in the course of the study. The approval of document content and consent to participate in the investigation was obtained by appending one's signature to the proposal and replying to the email sent out by the researchers.

The incorporation of both open-ended and closed-up questions were deemed to be one of the most effective approach to obtain concise responses $[63,74]$. Whereby appropriate open- ended questions were used in the semi-structured interview to avoid generic answers and to obtain detailed responses. For instance, "if yes/no, can you explai". following certain closed questions. Likewise, with the survey, although most questions were limited to single answer options, but some questions permitted multiple choices as well as text box entries with the option "others, please specif". so as not to limit participants responses for some crucial questions. All interviews were conducted in English and kick off date was from the first week of October 2020 and lasted for about 2 weeks. The proposed content of the interview, as well as the length of each interview mapped against relevant job classes were discussed with key personnel from each selected industry, minor adjustments were made according to the feedback obtained from participants. Based on feedback and practicality, interview durations were pegged to last for between 30-60 min depending on the information required from the participant based on their job class and level of expertise. Table 1 shows the characteristics of interview participants involved in the pilot investigation.

Table 1. Characteristics of interview participants involved in the pilot investigation.

$\begin{array}{r}\hline \text { Industry } \\ \hline \text { Manufacturing-cement }\end{array}$

Utilities-Water

\section{Category and Job Class}

A- Maintenance manager (mechanical engineering), reliability engineer (electrical engineering), finance manager (cost), health, safety and environment (civil engineering)

B- Maintenance supervisor (mechanical) maintenance planner (project controls)

C- Mechanical fitter, electrician

A- Maintenance manager (mechanical engineering), contracts and procurement

B- Method and inspection (electrical and mechanical), maintenance planner (project control)

C- Electrician

Where job Category A represents management staff directly involved in MoOSTs, B-staff involved in implementation of engineering methods and/or techniques and equipped with decision making ability during MoOSTs and $\mathrm{C}$-staff with experience with handling plant assets and knowledgeable on the schematics and working of the plant.

\subsection{Ethics Approval}

The study was conducted according to the guidelines of the Declaration of Helsinki, and approved by the Ethics committee panel of Mechanical, Aerospace and Civil Engineering Department, University of Manchester, UK (Ref code: 2020-8009-13470) and date of approval 9 March 2020.

\subsection{Sampling Technique}

Participants were selected through a purposive or maximum diversity sampling strategy, owing to the specificity of MoOSTs activities and the job classes involved. In addition, this sampling approach offers the opportunity to explore anthropological scenarios that can intuitively guide the emergence of new meanings [75]. In this study, the sampling technique 
selected was designed to meet the following predefined objectives; (1) to represent locations where the researcher could gain access to high number of participants involved in MoOSTs, who were also willing to participate in the study, (2) to reflect industries with very high to medium frequencies for performing MoOSTs, (3) to represent practitioners who have significant MoOSTs experiences, and (4) to include practitioners with decision making capacity based on their responsibilities during MoOSTs. It is worth mentioning that some organizations and participants who were approached declined participation due to work commitments and COVID-19 related restrictions. Interviews were conducted remotely and the links to the anonymized questionnaires sent out.

\subsection{Sample Size}

There are important factors to consider, when determining sample size including degree of accuracy (based on sampling error and confidence interval) as well as extent of variations with regards to important attributes of the study [61]. However, because a non-probability sampling technique, in this case purposive sampling was selected, randomization was not considered relevant but rather based on expert judgment. Hence, statistical assumptions about sampling errors do not apply [61]. In total, 49 carefully selected experienced practitioners in the UK, US and Nigeria working across diverse industries identified from a prior SLR in MoOSTs were selected. Figure 2 is a snapshot from the survey design and management platform that is authorized for use by the University of Manchester (i.e., Qualitrics) to depict the total number of completed responses received.

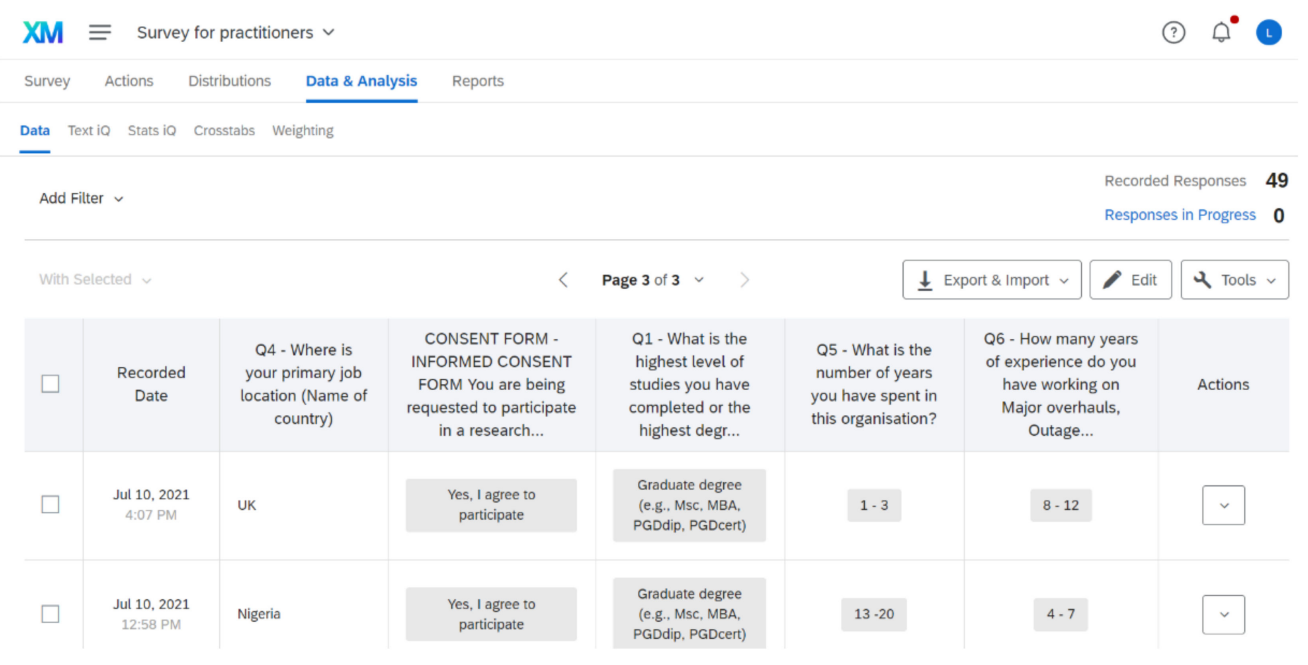

Figure 2. Snapshot from the survey design and management platform (Qualitrics).

Subsequently, after completion of the survey, interviews were conducted and each transcribed interview was entered into Nvivo 12 Pro software (QSR International, www.qsrinternational.com, accessed on 14 December 2021) for storing, and coding of data. Each transcript was read several times, and based on the coding strategy, themes emerged. The themes were formed from combination of perceptions, responses, or experiences related to the questions on the management of MoOSTs from the professional's perspectives based on theoretical constructs including but not limited to these areas from within literature, overview of MoOSTS [10,69] delays in MoOSTs [70] and knowledge management in MoOSTs [7]. During analysis some themes were submerged with other themes, while some were discarded or reframed as data supporting each decisions emerged. Figure 3 is a diagram that depicts the buildup to the development of thematic analysis coding process using the Nvivo (12) software. 


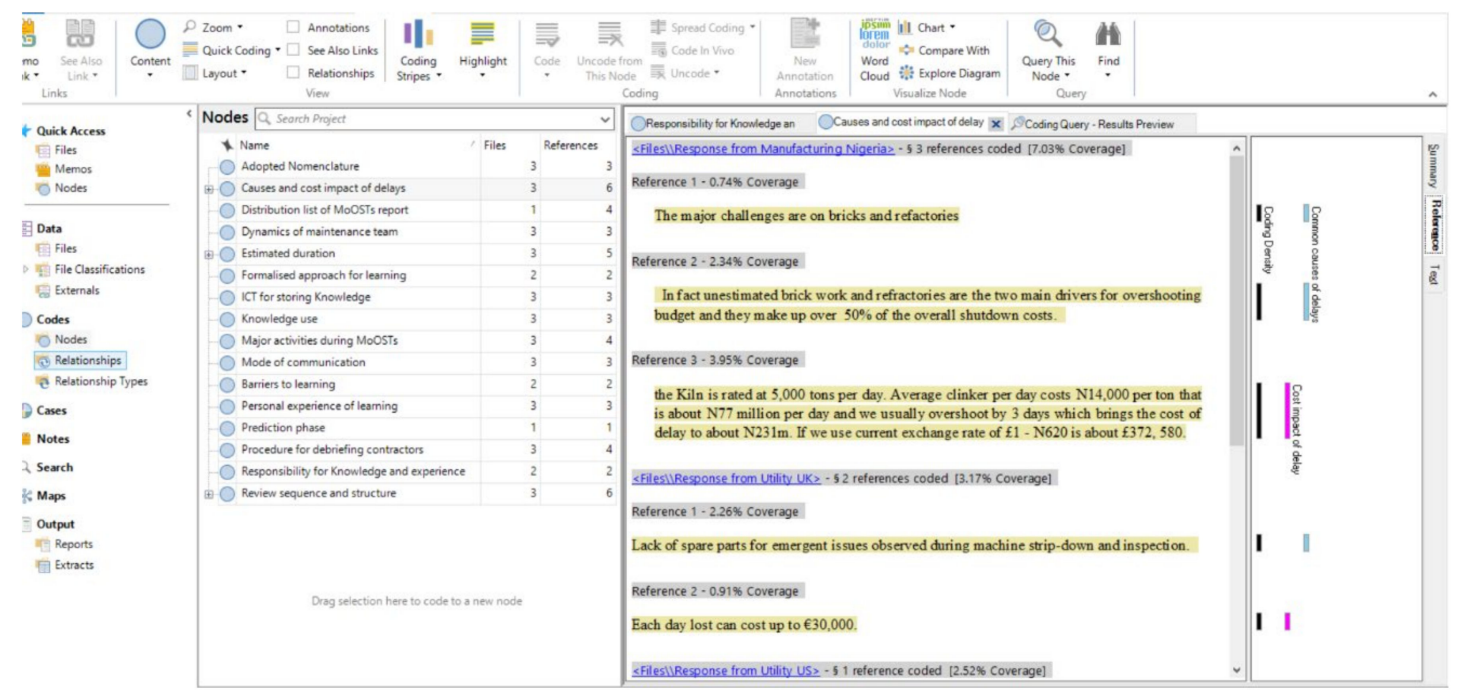

Figure 3. Illustration to the build-up of thematic analysis coding with Nvivo (12) software.

\section{Data Analysis}

This section highlights the data analysis methods utilized for analyzing data collected from the survey and interviews. The results emanating from both methods are depicted and rationalized.

\subsection{Data Analysis of Survey Response (Frequency Analysis)_Participant Demographics and MoOSTs Characteristics}

The representation of demographic data collected from the survey, with specific information on participants including, academic levels, job class, industry, location of operations, remaining years until retirement, as well as total number of MoOSTs performed are depicted in Figure 4. A frequency analysis method [76], the most widely adopted method to efficiently organize the descriptive data were utilized. In this technique frequency charts were widely used to represent the frequencies of the data.
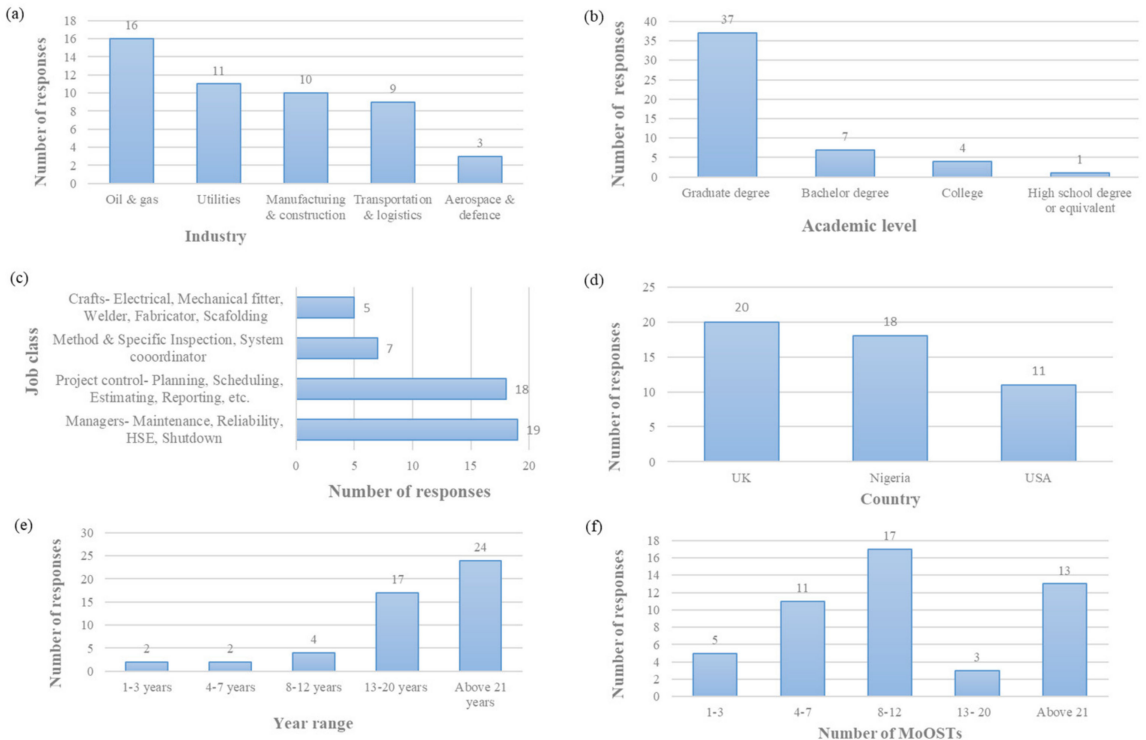

Figure 4. Participants' demographic information. Notes: (a) industry of operation; (b) academic level; (c) job class; (d) location; (e) number of years left till retirement and (f) number of MoOSTs performed.

Participants involved in the study were located in three countries, with the UK having 20 participants, 18 from Nigeria, and 11 from the USA, representing distributions of 
a fully industrialized country (USA), majorly service oriented (UK) and import based economy (Nigeria). Among the pool of participants, 37 of them, representing (75.5\%) of the total number of participants had post-graduate degrees. Another seven (14.3\%) had at least bachelor's degree, this showed selection of high academic literacy among participants. Likewise, 19 participants (38.8\%) held managerial positions although their background were within core engineering disciplines of mechanical, electrical, civil as well as in environment, health and safety (EHS). In addition, 18 participants $(36.7 \%)$ held job roles in project controls, a crucial job class in MoOSTs. These selections reflected the desire of the researchers to interview participants with high technical expertise and decisionmaking capabilities during planning and execution phases of MoOSTs. Participants from oil and gas were 16 in total representing 32.7\%, utilities were 11 (22.4\%), manufacturing and construction-10 (20.4\%) and transport and logistics-9 (18.4\%). The major aim of recruiting participants from these industries being to reflect industries where there are high and medium frequencies for performing MoOSTs. The number of MoOSTs that each participant has been involved in was included in the survey to obtain years of experience, five participants chose the 1-3 years option (lowest number of years) and thirteen participants chose the option for above 21 years (highest number of years).

The frequency for performing MoOSTs across the five industries were highlighted, six participants $(12.3 \%)$ indicated 0-6 months as the time interval between cycles, 10 participants $(20.4 \%)$ went with the twice a year option, another $13(26.5 \%)$ indicated frequency of once a year, 10 participants $(26.5 \%)$ selected the once every 2 to 5 years frequency option and $7(14.3 \%)$ indicated a frequency of once every 5 years and above. The huge capital intensiveness of MoOSTs activities were scoped against the total maintenance budget, $23(57 \%)$ of responses acknowledge that estimated MoOSTs costs could be as high as $11-50 \%$ of maintenance budget representing huge capital costs which if managed improperly would significantly impact on the organization's profit and loss statement of account.

The huge number of labor requirement which characterizes MoOSTs was a critical element that needed to be examined. The number of personnel peaks during the execution stage whereby manpower requirement may reach up to 1000 or more depending on plant size, technology and scope of work [77]. Hence, the estimated number of staff involved in MoOSTs within the maintenance organization, which could be a fraction of the entire labor due to outsourced labor in very large and complex cycles was examined. Consequently, the estimate of sub-contracted activities from the total number of maintenance activities during MoOSTs was also examined. The percentage of staff turnover in MoOSTs, which examined probable rates of knowledge loss within the organization was included in the questionnaire. Finally, the main causes of delays during MoOSTs were examined, from the available options each participant could select more than one causes of delay. The causes of delays and budget overspend were discussed at length in [78], based on the responses, 22 participants selected unplanned work, 32 selected discovery work, 15 went for inaccurate allocation of time and resources within the schedule, 17 chose labor, spares and materials delays, five selected weather or adverse environmental conditions. An extra element of delay has been introduced due to emergence of the COVID-19 pandemic five participants went for this option. Figure 5 depicts the specific MoOSTs related information obtained from the survey responses. 

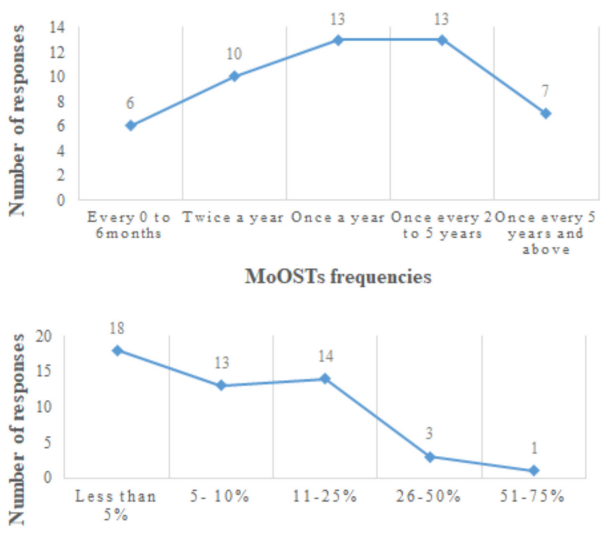

(e)

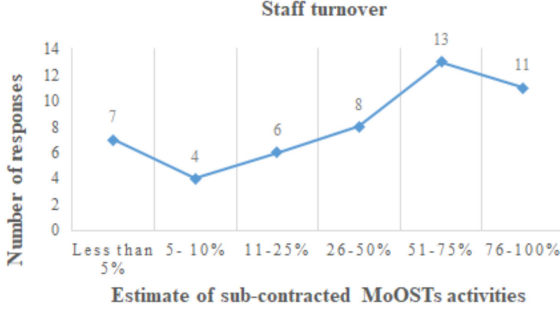

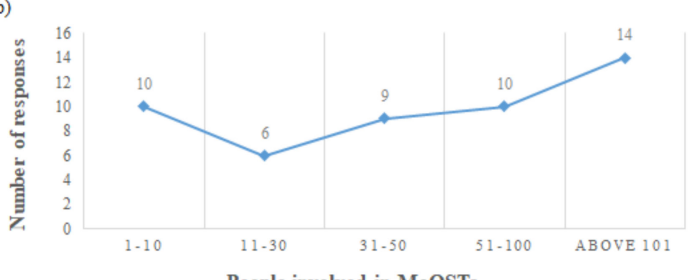

People involved in MoOSTs

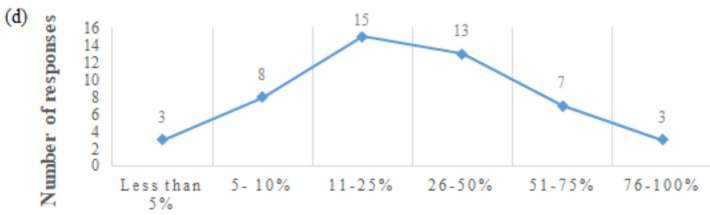

Estimate of MoOSTs budget

(f)

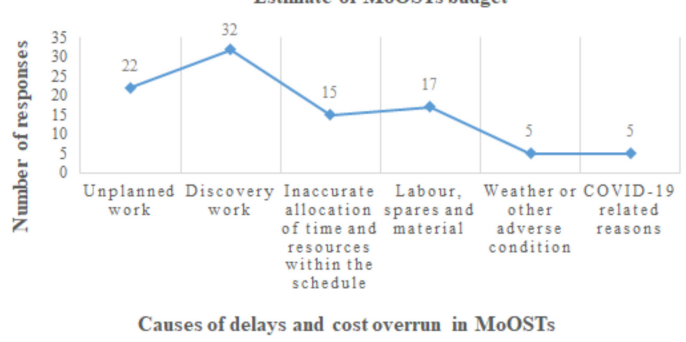

Figure 5. Specific MoOSTs related information obtained from the survey. Notes: (a) frequencies for performing MoOSTs; (b) people involved in MoOSTs within the maintenance organization; (c) turnover of staff involved in MoOSTs; (d) estimated cost of MoOSTs as a percentage of the entire maintenance budget; (e) estimate of sub-contracted MoOSTs activities in different industries and (f) major causes of delays and cost overruns (participants could select more than one reasons).

Literatures in the body of knowledge highlighted loss of expertise due to staff retirement or high staff turnover as major risks facing project environment $[24,79]$. Therefore, a crucial information that was obtained from participants was to determine how much time they had before retiring and comparing responses across job class, in order to identify job class that were most at risk from losing expertise in future. Figure 6 is the cross analysis of responses received between the number of years left for retirement mapped across relevant job classes.

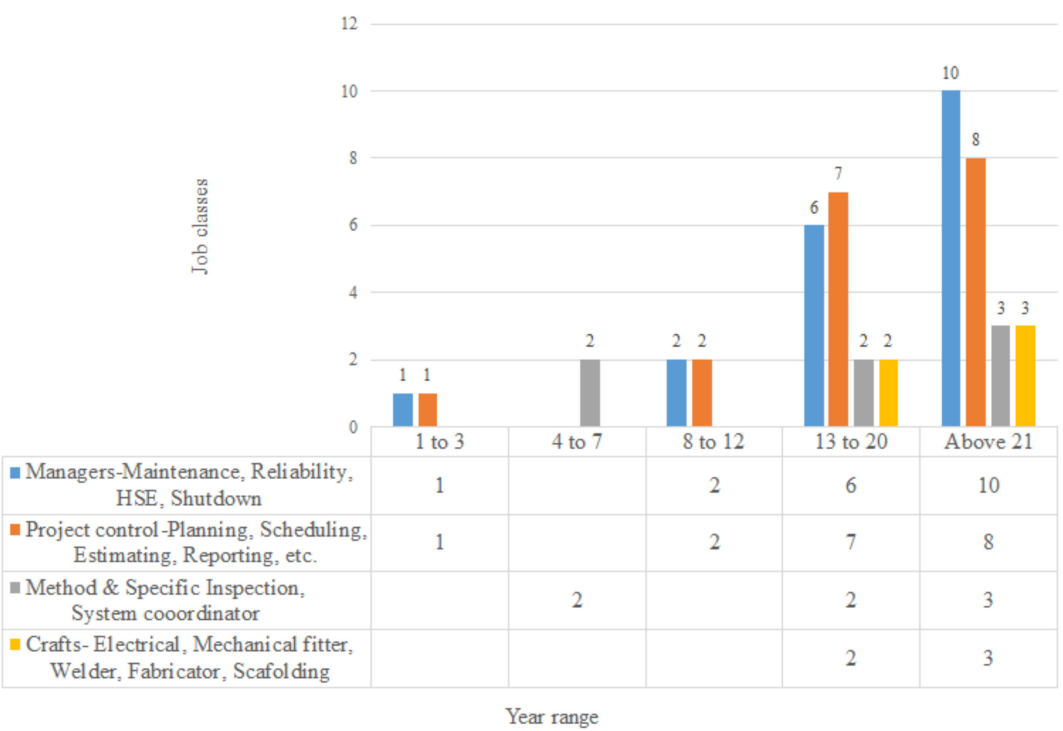

Figure 6. Number of responses based on cross analysis of job class and years before retirement. 
The responses from participants indicated that although 13 participants $(26.5 \%)$ had performed above 21 MoOSTs but just two participants (4.1\%) had 1-3 years left before retiring. This was despite the pool of highly experienced professionals included in the study. The probable implications might include that, if knowledge management and experience transfer are prioritized in the nearest future, there is still time for experts to contribute to the knowledge pool and for new entrants to adapt.

Further analysis undertaken to determine the link between MoOSTs frequencies across industries, was to determine correlation with literature. The determination of the predetermined time horizon for performing MoOSTs is based mainly on the mean time to fail of the production systems, and this can vary from plant to plant as well as across industries [80]. Figure 7 is a cross analysis of responses of participants based on frequency for performing MoOSTs and industry.

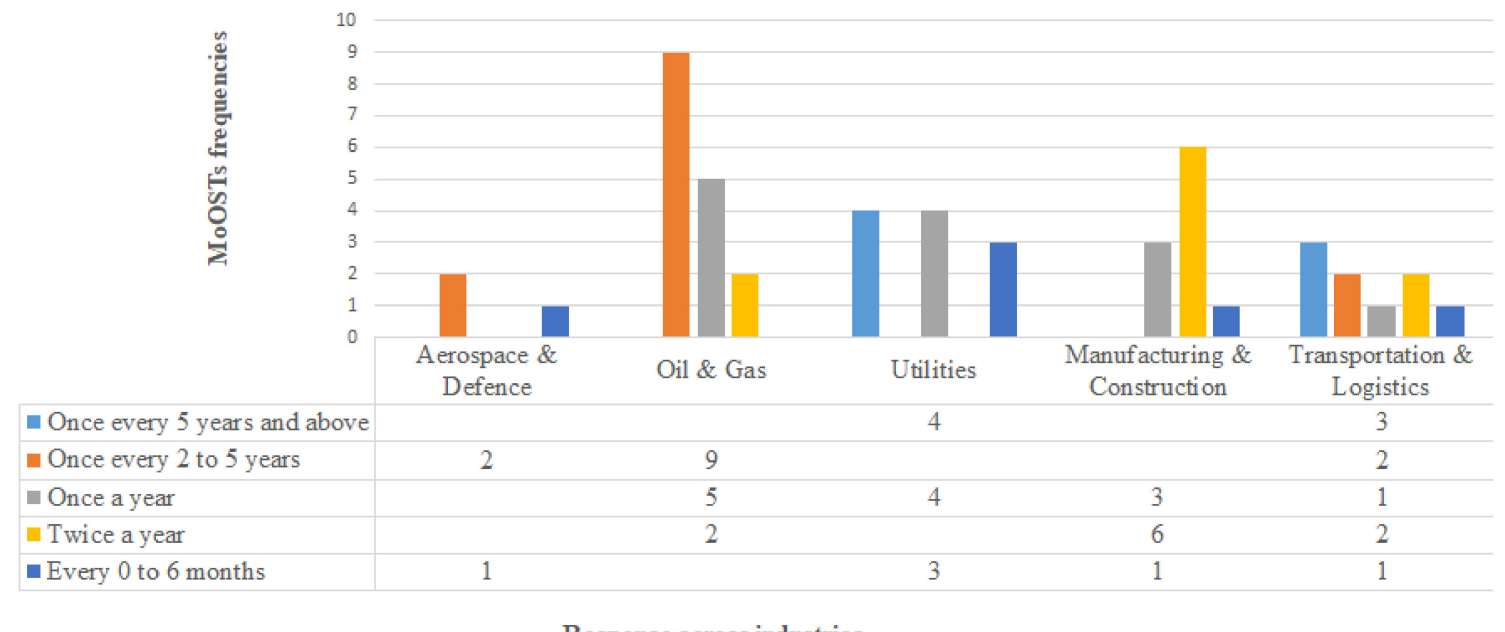

Figure 7. Number of responses based on cross analysis between frequency and industry.

Furthermore, participants were asked to select common documentation and reporting approaches implemented to manage knowledge and document lessons learned during MoOSTs in their respective organizations. Figure 8 shows the distribution of these responses.

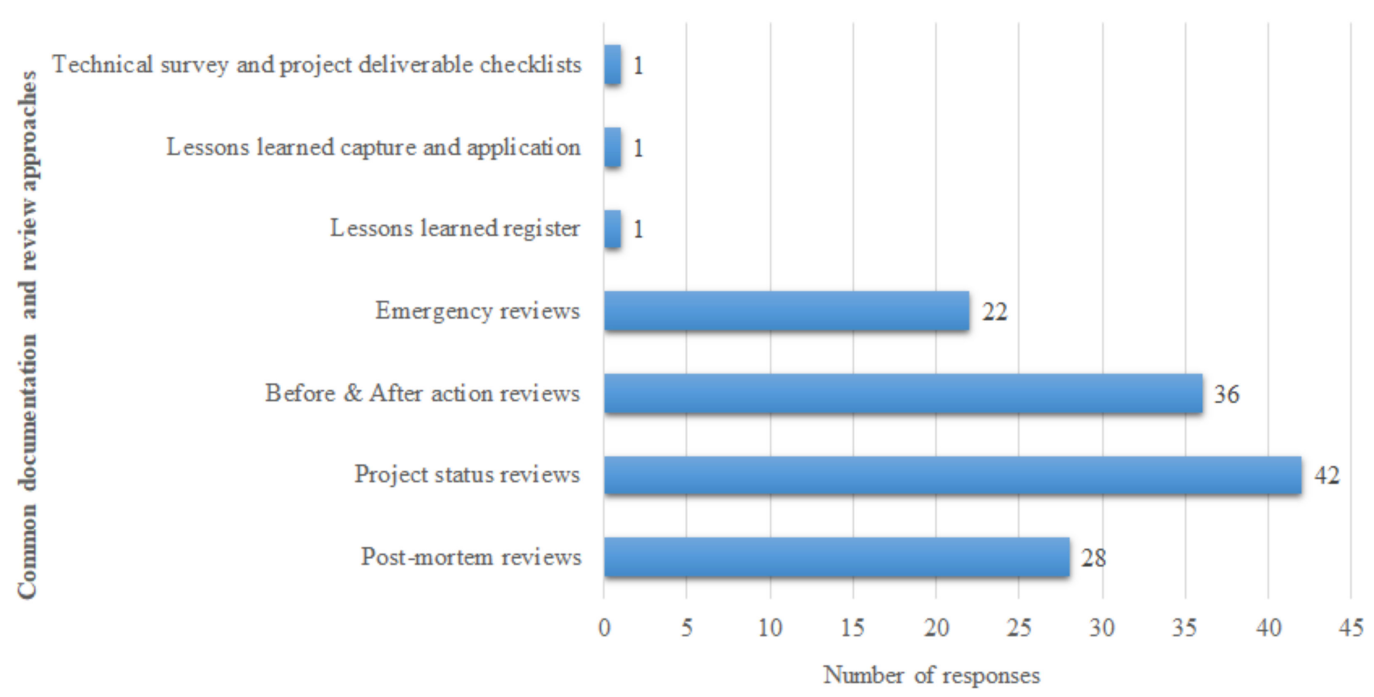

Figure 8. Analysis of responses obtained for common documentation approaches during MoOSTs. Note: participants could select more than one option for this question. 
Finally, because decision makers involved in MoOSTs have to balance critical factors including but not limited to, time, cost and quality of work [81]. In the event of delays and reworks which could arise due to many reasons including but not limited to, unplanned work as well as poor quality of works, the probability of cost overruns is increased. Participants were asked to choose estimates based on the percentages of MoOSTs that had exceeded timelines or costs in contrast with estimates for MoOSTs that had been completed ahead of scheduled timelines and below cost. Their responses are displayed in Figure 9.

(a)

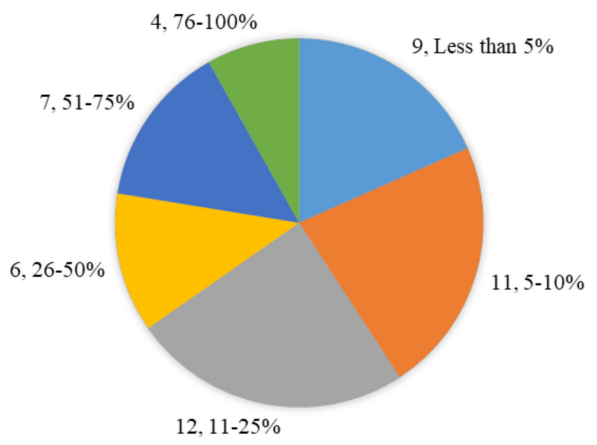

(c)

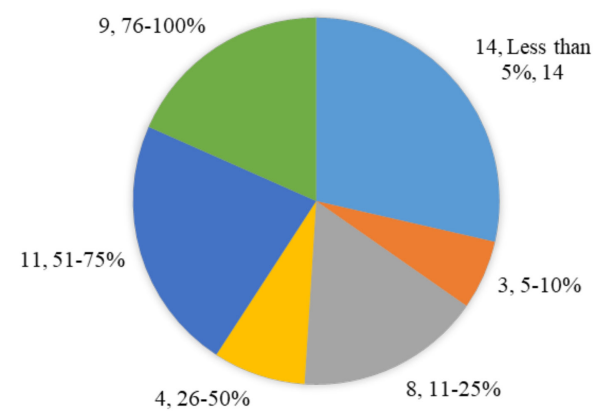

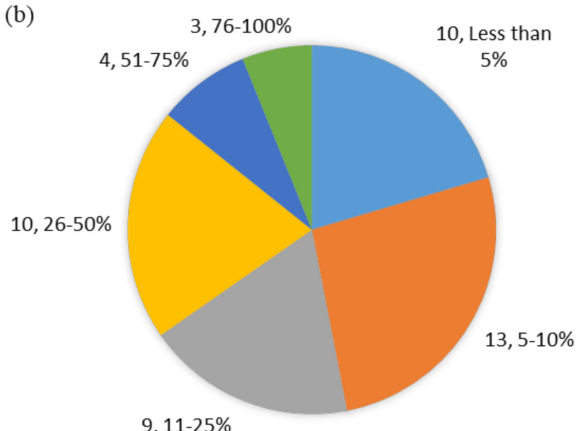

$9,11-25 \%$

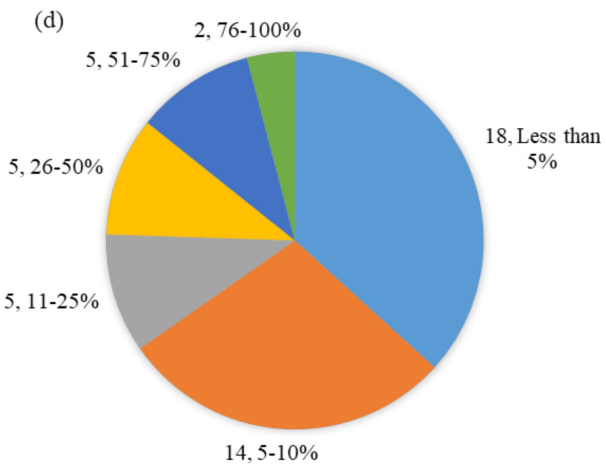

Figure 9. Analysis of responses obtained for estimated timelines and cost during MoOSTs. Note: (a) Number of responses and percentage of MoOSTs that exceeded estimated timelines; (b) number of responses and percentage of MoOSTs that exceeded estimated cost; (c) number of responses and percentage of MoOSTs that have been completed ahead of estimated timelines and (d) number of responses and percentage of MoOSTs that have been completed below estimated cost.

\subsection{Data Analysis of Semi-Structured Interview-Thematic Analysis}

Thematic analysis (TA) is a method of identifying, analyzing and reporting patterns (themes) within data [82]. The popularity of TA is partly due to its ability to explore variety of research questions and topics at a level of depth that quantitative analysis lacks, while offering flexibility in interpretation of data. However, the application of TA, needs to be carefully performed under the watchful eyes of an experienced researcher. In general, analysis of qualitative data could be outlined in five steps; compiling, disassembling, reassembling, interpreting, and concluding, which are described within the thematic analysis process [83].

The first step, compiling the data into a usable form include, transcription of interviews and it is recommended that this exercise is personally performed by the researcher, to engender familiarization with data [64]. In this study, data from the interview sessions was automatically transcribed by the technology utilized for conducting interviews remotely. However, the transcripts, was read and re-read many times to ensure that all responses and intended meanings had been captured accurately. The next step, disassembling of data involved tearing the data apart and creating meaningful groupings. This is often achieved through coding. According to Sutton and Austin [84] coding, is defined as "the process by which raw data are gradually converted into usable data through identification 
of themes, concepts or ideas that have some connections with each othe". A coding strategy can be established before the coding (priori) begins based on review of literature, or it can be an open or emergent meaning that is created as coding ensues, which develops during the coding process [83]. Another coding strategy is "in-vivo" coding approach that uses phrases from participants' descriptive responses. In this study, a combination of coding strategies was taken into account, definition of codes based on literature were identified and supplemented with emerging codes from the interview data. The third step is reassembling, which requires that codes are mapped against a context to create themes (characteristics). In this context, a theme captures all important aspects about the data with respect to the research question. Examples of output from the qualitative data analysis software "Nvivo" having applied the five steps within TA process is depicted in Figure 10 as a word cloud diagram of interview responses alongside a node comparison of responses.

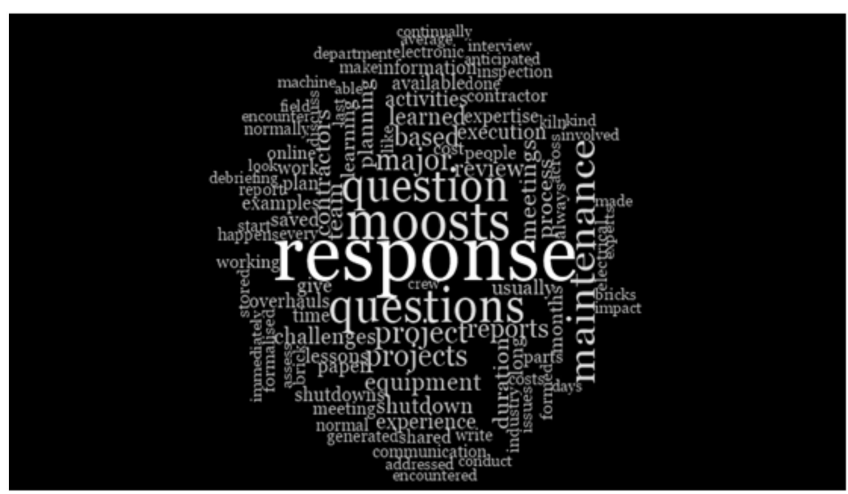

a. Word cloud diagram of interview responses

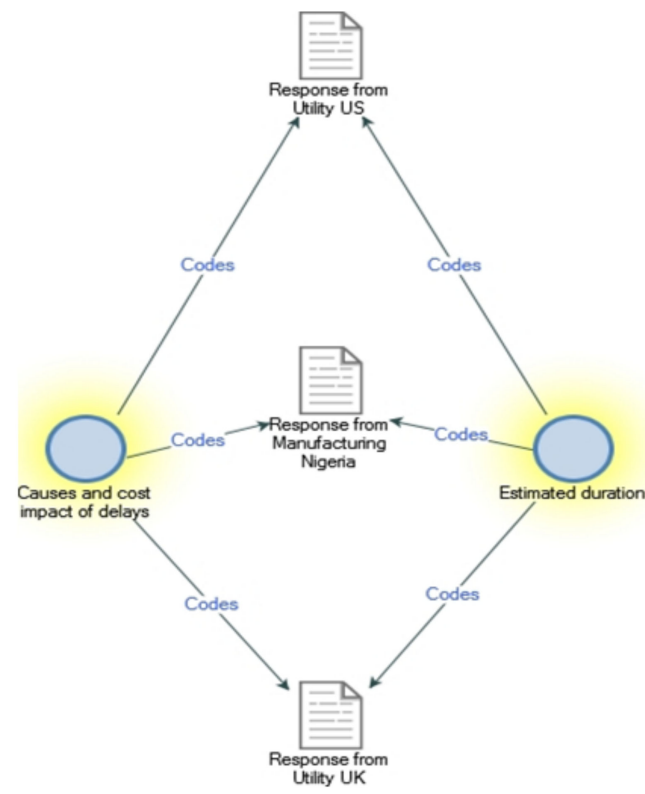

b. Node comparison of responses

Figure 10. Word cloud diagram of interview responses and node comparison of responses obtained from Nvivo software.

A very critical step in TA, is interpreting the reassembled data, and it involves making analytic conclusions based on the data presented as codes and themes. Although it might feel that steps leading up to a TA are listed in liner sequence, but it does not mean that interpreting occurs after the first three steps, rather it is performed concurrently along with other steps within the TA process [85]. The final step is concluding, which involves examining responses to the research questions or study objectives. The interview questions guide for the semi structured MoOSTs practitioners interview can be found in Appendix A. The summary of the nine themes that emerged from data analysis exercise and selected illustrative data extracts from interviews is discussed as follows:

Theme 1: Nomenclature

This theme describes the adopted nomenclature for comparable large-scale maintenance activities across industries. Based on responses from participants, for maintenance activities commonly referred to as major overhauls in the utility industry, turnarounds in the oil and gas industry and shutdown in cement manufacturing.

"... in the utility industry (e.g., water distribution/sewer collection and treatment) we conduct maintenance and overhaul on large pumps, motors bar screens, large exhaust fans, tanks, dams, compressors, transmission/distribution pipes and reservoirs". Maintenance planner, utility plant, US 
"... in cement manufacturing, we have major maintenance for Kiln shutdown KSD, some call it major overhauls". Reliability engineer, manufacturing plant, Nigeria

"... shutdowns of the bulk work". Shutdown manager, manufacturing plant, UK

Theme 2: Mode of communication

This theme described the prevalent mode of communication across MoOSTs organizations. Due to the emergency of COVID-19, most of the participants interviewed stated that their organizations had fostered the gradual transition from paper-based communication to electronic system to remote working, while introducing social distancing measures where possible.

"Since COVID its move things forward and move them on dramatically and it's a massive improvement, where we will have a small number of people in a room and then everybody else joining via teams so we can have can have large numbers of people at the meeting and only a small number in a meeting room. We've got better control over our meeting". Maintenance manager, manufacturing plant in UK

"It used to be paper based probably, but now we're pretty much fully electronic". Document controller, transport and logistics plant, UK

"Since obviously COVID-19 happened and we couldn't have lots of people in one room while we used to do this before, now the online shutdown meeting I mean, so now the contractors, usually the supervisor were issued with like an iPad or similar." Knowledge expert, manufacturing plant, UK

"So a lot of it's now electronic ... there's very, very little paper because it's not a live document once you print something off, you know there's any changes to it and it can be tracked." Overhauls planner, utilities plant, US

Theme 3: Dynamics of maintenance team

The responses from participants were split across industries, for instance, in manufacturing, where there were likely to be backlogs and complexity in maintenance tasks, there was an understanding that relevant expertise might need to be sub-contracted based on maintenance demands. On the other hand, activities performed in utility industry was more predictable and the team was fairly stable.

"You know, we might go through a period of three or four years of using someone then we've done a lot of that work, and then we've gained this skills ourselves to be able to then supervise it ourselves. Alternatively, we get a different expert in to then help us with the next part, once we gain the skills we can then do the work going forward and it's sort of picks up like that". Maintenance supervisor, manufacturing Plant, UK

"We don't have specific people that do shutdown, we normally categorize the task based on what we can do in house and what we sub contract ... " Contracts manager, Aerospace, UK

"The maintenance crew hardly changes. We do have our own internal mechanical, electrical, PDM and instrumentation maintenance crew that conduct maintenance on the assets/equipment". Maintenance manager, utilities plant, US

Theme 4: Impact of delays

This theme reflected the financial implications and reputational damage that might occur due to delays in major maintenance activities. This is of particular importance, due to the plant being offline and additional pressures from production/operation to get the plant back online.

“... that would be on production called (CPD), cost per day, if we overshoot, just the circumstantial losses for the plant could be in the range of say $£ 100,000 "$. Maintenance manager, utilities plant, UK

“... the Kiln is rated at 5000 tons per day. Average clinker per day costs N14,000 per ton that is about N77 million per day and we usually overshoot by 3 days which brings 
the cost of delay to about N231m. If we use current exchange rate of $£ 1-N 620$ it is about $£ 372,580$..." ". Maintenance planner, manufacturing plant, Nigeria

"Each day lost can cost up to $€ 30,000 "$. Maintenance manager, utilities plant, UK

Theme 5: Causes of delay and overspend

A major challenge for maintenance organizations within continuous production industries is an inability to envisage the whole maintenance activities that need to be performed during MoOSTs. Despite advances in condition monitoring and diagnostic tools, it is often difficult to predict the actual state of an equipment. Other common characteristics of this theme identified were lack of spares, large number of people working on site performing complex tasks and more recently COVID-19 restrictions and social distancing requirements.

"In fact under-estimated brick work on the refractories are the two main drivers for overshooting budget and they make up over $50 \%$ of the overall shutdown costs". Maintenance supervisor, manufacturing plant in Nigeria

"Bit of guesswork until we can get in and have a look at the real work to do yeah, yeah, exactly ..." Reliability engineer, manufacturing plant in UK

"If it's not supervised correctly and things like quality of work can be affected, it can extend the shutdown if you don't keep on top of that". Maintenance planner, water utility plant in the US

"The main delays can be where we have got too many people working in one area, and obviously this COVID-19 time, it was even more challenging to ensure we can maintain a safe work area. For instance, you could have mechanical team and then the scaffold team and it could be difficult to fit everyone". Shutdown inspector, oil and gas, Nigeria

Theme 6: Responsibility for knowledge maintenance and experience management

To develop this theme, several research-based articles [86,87] and follow up questions were imbibed. In the context of this study knowledge maintenance and experience management process describes capture/collection procedures, which include developing suitable templates for capturing learning events and identifying critical MoOSTs activities. Subsequent activities would entail a filtering process before storage, that is, verification of knowledge and/or learning experience that has been captured, this could be by same person responsible for capture, a superior or across specific teams. There would be deliberations in between regular project meetings during MoOSTs (for live capture) and in debrief session after MoOSTs (after termination) to obtain required information. Classification, storage and publishing rights might be allocated to a team collectively or assigned to an individual. Responses obtained from the interview, showed that some organizations (Utilities plant in the US, Railway, UK) take a more collective approach towards knowledge maintenance process (capture, filter and storage), whereby anyone could write post-mortem reports upon MoOSTs termination, then filter, verify and store in appropriate knowledge repositories. On the other hand, some of the case study organizations (aerospace in the UK and cement manufacturing plant in Nigeria) assigned responsibilities for these actions, in most cases this could be anyone within these job classes, planners, document controller or even maintenance overhauls manager. Furthermore, ease of retrieval and adaptation to existing knowledge was examined and responses on how knowledge was accessed or shared obtained. Responses varied across skill levels, while some participants higher up in the hierarchy of skillsets stated that they had access to knowledge platforms (share-point sites, intranet and web-database). On the other hand, participants who were further down the hierarchy of skillsets, for instance crafts/trades, depended on minutes/briefs that were in circulation electronically via emails or paper based. However, because knowledge captured today could become irrelevant or outdated in future, there needs to be a process for reviewing and updating existing knowledge, it enables deleting and/or updating functions. Responses from industries such as manufacturing as well as oil and gas highlighted that knowledge reuse process occurs during debriefs upon MoOSTs termination when learning experiences are shared, audit reports developed, and performance reviews concluded. 
"Someone will be giving ownership of certain different parts. The person that's either has a vested interest in it or is most suited". Reliability engineer, aerospace and defence, UK

"We do not write reports, however before the project commence, the maintenance planner must create a job plan for the job". Method and specific inspection, transport and logistics, UK

"The true purpose of the debrief exercise is to make sure that when we start the preparation and planning for the next major repair that we can put actions and recommendations in where we can improve and the report will be stored in our local network". Maintenance manager, manufacturing plant, Nigeria

"... The plan is constantly fluid and live. I update the plan two or three times a day and then feedback that information. This could hamper the reuse of previous reports cause things are constantly changing". Shutdown planner, manufacturing plant, UK

Theme 7: Personal experience of learning

The main purpose for this theme was to deduce MoOSTs elements that have influenced participants' learning the most. Common modalities associated with this theme were but not limited to, repetitive task linked to most MoOSTs activities, limited reflections after each cycle to pinpoint highs and lows, familiarization with asset operations were the general perceptions held by interviewees.

"Yeah, so just from having knowledge of this plant and knowing the whole operation. So it boils down to the fact that you like understand the operations of the plants and you're familiar with the assets and things like that. So it's not just textbook knowledge". Inspector, utilities plant, US

"I learnt from repetitive tasks, from personalized training and the company policy of shuffling me to different projects from my early career". Maintenance planner, manufacturing plant, Nigeria

"I would say it is just from lots of experience and debriefs, as well as understanding the plant and the contractors. Then I would say continuous reflections plays a big part in how successful major repairs are. Team work and collaboration is vital". Maintenance manager, manufacturing plant, UK

Theme 8: Lack of formalized approaches for knowledge capture and transfer

This theme is related to identifying formalized means for knowledge capture and transfer. Participants described approaches that were informally practiced such as shadowing, coaching, peer assists, observations and mentoring. The perceived effectiveness of common approaches being practiced in most industries that perform MoOSTs was a feeling of inadequacy. A few responses captured the feelings among practitioners, who felt that a more formal approach of what they were doing now in terms of mentoring, peer assists, shadowing, etc., could be beneficial.

"There is a lack of formalized training, so for example on the production team, if you start as a new member, the production team just the whole system where you go and do so many months in one area. ... So you're rotated round until you've witnessed all those bits. There doesn't seem to be that in the maintenance out as much". Maintenance manager, manufacturing plant, UK

"... to answer, I think it'll just be you shadow someone that's done it before you learn from their experiences and things like that, you know you sort of have to catch up quickly". Reliability engineer, manufacturing, UK

“... there's never been any formalized training on it". Inspector, manufacturing plant, Nigeria

"There's not a formalized training, probably just time and experience, but also spending time with other people". Document controller, utilities plant, US 
"I would say we have means people can learn from the team but it is not formalized, so it would be much more done through shadowing, mentoring and your peers assisting you". Maintenance manager, utilities plant, US

Theme 9: Barriers to learning

Barriers to learning is quite popular in the study of major maintenance activities, to further develop the coding strategy and understand emerging attributes from data, follow up questions based on participants' responses and sign post from relevant studies [30,88] were imbibed. A consistent response from participants was that there was not enough time for reflections to engender learning. Some practitioners cited inability to capture knowledge gained from one cycle to another cycle in solving similar problems or applying similar logic to different problems as limitations. A typical follow-up question to obtain the perspective of participants examined if there were peculiarities within their respective organizations that might aggravate the impact of such limited adopting of projects to learning when compared, for instance, with another organization within same industry. When responses were analyzed common assertions among some participants was that majority of maintenance activities involved in MoOSTs are routine, they highlighted lack of activities prioritization based on reliability engineering and maintainability objectives as critical factors. Rather, the norm was to assign MoOSTs objectives and criticality in activities critical paths based on project objectives obtained through mathematical analysis, (usually a "forward pass," "backward pass," and "float calculation"). The effect of adopting traditional project-based objectives might limit the examination of critical activities in MoOSTs if the aim is to engender experience-based learning [89]. Furthermore, lack of ownership was identified as a main barrier to learning, because MoOSTs are labor intensive, substantial number of outsourced resources are committed towards each cycle. The perception and agenda of an employee within MoOSTs organizations contrasts with that of an employee within the employment of a contractor. Typical responses of regular employees, would be that they identify areas where they require additional expertise and outsource those activities, leaving little or no room for expertise development within the organization. On the other hand, the responses of employees contracted out to different sites would identify lack of tasks continuity, coherence in organization culture, and motivation as barriers to learning.

"I would say Time!! It takes time to reflect and look at what you are doing and some people have that ability while others don't also quite often people get caught in the moment and just become like a conveyor belt in the work without giving much thoughts to what they are doing. Cause you never stop, you finish one shut down and go back to start another one. It is almost like a roller coaster of never catching a break". Reliability engineer, manufacturing plant, UK

"Not documenting and sharing the lessons learned is a major problem because there is no time. When a maintenance team moves on, the lessons learned are not transferred to the next generation. In my opinion, a barrier to learning from experience results from maintenance teams with too few members not having the time to document the lessons learned. Organizations need to understand the value of documentation practices and resource them appropriately". Document controller, manufacturing plant, UK

"There is the gap from the individual aspect and organization, if the system is there to encourage but the individual impacts on the overall efficiency and the duration of learning, and it is the major obstacle for passing down key skills learned from major overhauls". Maintenance shutdown manager, manufacturing plant, Nigeria

"It's a tough one, isn't it? I think previously, maybe just before my time or just as after I started do it, almost a hesitancy for people to share knowledge". Inspector, utilities plant, UK

\section{Discussion of Findings}

In this paper, the challenges of managing MoOSTs-related knowledge have been identified and probed to highlight underlying causes. The identified challenges were 
mapped to key demographic information of participants such as, qualifications, level of expertise, job class, industry, years of experience, size of organization, staff turnover, and location. This mapping is useful for the development of real-life knowledge management initiatives because it offers insights on where research efforts should be concentrated. For instance, the mapping exercise highlights industries and job classes across the different regions that are at risk of losing expertise, based on factors such as years left to retirement and/or staff turnover rates. This is critical because experienced practitioners contribute immensely to successive MoOSTs cycles to enable achievement of predetermined outcomes, but for some organizations this poses the risk of losing knowledge if they are unable to identify, capture, prioritise, store and reuse knowledge as well as expertise before it becomes unavailable. The type of expertise within the consciousness of experienced practitioners is determined largely by the type of activity and or responsibility assigned to them. Staff with job autonomy in highly critical industries develop personalized approaches to performing tasks [88]. However, such types of personalized approaches to performing tasks in this instance during MoOSTs might lead to "expertise-silo effects" which inadvertently poses risks to the organization. These risks are further aggravated partly due to several reasons, including when knowledge and expertise are possessed by outsourced human resources (usually due to the large volumes and specialisation of MoOSTs activities). Other cogent reasons might be losses due to staff resignation and/or departure, as well as hesitancy to share knowledge because knowledge is rationalized for power bargains, and those in possession hoard it to retain relevance within organisations [49].

For the first research question, nine themes emerged and six were associated with the challenges of managing knowledge during execution of MoOSTs activities in practice. The results show that these themes; responsibility for knowledge maintenance and experience management, barriers to learning, lack of formalized approaches for knowledge capture and transfer, personal experience of learning, dynamics of maintenance team and modes of communication, have significant impacts on how effectively knowledge is managed during MoOSTs.

For the second research question, it was observed that while most of the identified challenges from the SLR matched the findings from this study, this study further probed underlying causes of these challenges as well as new themes that had emerged. For instance, in terms of these two themes; responsibility for knowledge maintenance and experience management, and the lack of a formalized approach to knowledge management and experience transfer within MoOSTs organizations, the responses obtained highlighted that knowledge currently lies with experienced practitioners that are involved with MoOSTs. Hence, organizations with limited abilities to harness this knowledge are increasingly at risk. Further probe of this phenomenon indicated that most of the professionals interviewed in this study who are highly experienced and equipped with good working knowledge of their respective plant operations (a major pre-requisite to being selected into MoOSTs organizations) was a true reflection of MoOSTs organisation in practice. The high level of expertise might lead to decreased motivation within organizations that have intentions to establish formalized approaches for tacit knowledge capture and learning form experiencebased frameworks. This might be because, decision makers are of the assumption that there was limited usefulness in groups of highly experienced professionals who most likely are perceived not to require any formal training to kick start their role. The perception from most professionals interviewed was that compared to how knowledge is captured and learning from experience developed within production/operations, by means of job rotation across different systems and/or areas, in MoOSTs, there are no such formalized approaches. However, experience is gained overtime from familiarization within the plant as well as assessments of lessons learned from failures and/or successes in prior MoOSTs cycles. Furthermore, due to the limited focus on knowledge management and transfer of expertise, professionals involved with MoOSTs are not adequately trained to imbibe formalized approaches for capturing and transferring their experiences over time. In terms of barriers to learning, participants were of the opinion that the chaotic environment during MoOSTs restricts sharing. Some professionals described their feelings towards MoOSTs 
as likened to being a part of a "conveyor system". That is, there is hardly any time for reflections during MoOSTs because you are constantly racing against time to handover to the production and operations team under very strict and sometimes unrealistic timelines as well as cost control measures. Afterwards, the new cycle of pre-planning activities for the next MoOSTs commences, which is more prevalent among industries where MoOSTs frequencies are reasonably higher (e.g., the cement and rail transport industries) [57,90].

For the third research question, it can be stated that insights provided from this study would provide significant inputs for developing a conceptual proposal for managing MoOSTs. For instance, the barriers to learning and managing knowledge that were identified from both literature and practice, a crucial step would be to prioritise (rank) factors that contribute to the barriers to knowledge management and deploy mitigating actions that would have significant impact scores. Furthermore, it was observed that for most organizations, scant attention is paid to determine which of the MoOSTs activities have the most critical impacts on successful outcomes. Hence, one of the necessary actions when developing a MoOSTs knowledge platform would be to enable the identification of critical MoOSTs activities to maximise knowledge capture from critical MoOSTs activities. Another, important perspective obtained from this study is the fluidity of MoOSTs plans, which is constantly updated as soon as the plan goes live, sometimes up to two to three times daily, hampering reuse of previous knowledge. In the words of one such participant "the schedule becomes outdated and needs to be updated once we go live and discover some jobs we have to do". Based on this need, any proposal for developing a MoOSTs knowledge platform will need to be agile to manage the demands of the users as well as provide complementary solutions for prognosis and enhanced decision-making during MoOSTs, with intentions of establishing criticality ranking for individual activities as this can provide information leading to continuous improvement and learning from experience.

\section{Concluding Remarks and Proposal for a MoOSTs Knowledge Platform (KP)}

The observations and underlying causes obtained from this study presents the opportunity to develop a proposal for a knowledge platform that can effectively manage challenges in MoOSTs development. Following analysis of the ample evidence obtained, it is evident that while mechanisms within existing MoOSTs databases and information management systems for identifying lagging indicators (generating audit and/or post-mortem reports, as well as suggestions for measuring and storing such captured information) exist, their ability to support prognosis and sustainable management of tacit knowledge for enhanced decision-making are quite limited. Therefore, it is necessary to establish the usefulness of large-scale information gathering within MoOSTs and further optimisation by first developing an approach for critically analysing important parameters within MoOSTs activities, based on the identified expert criteria. Upon identification of critical MoOSTs activities, an awareness of the useful expertise that needs to be captured and the sources for capture as well as KT process is will then be initiated.

Secondly, develop a conceptual framework that can be demonstrated with the use of a case study with the aim of building an integrated web-based knowledge platform (KP) for managing both tacit and explicit knowledge during the execution of MoOSTs. The integrated web based KP should be developed with many objectives, mainly to foster the retention of knowledge possessed by experienced professionals, to overcome real-time knowledge capture limiters especially time restriction and chaotic MoOSTs environments. Additionally, the web based KP would enable integration with other IT systems, especially existing enterprise resource planning systems used for managing MoOSTs and maintenance in general. The proposed KP should be simple, flexible, concise, and inexpensive. Consequently, it is imperative to intensify research efforts towards attainment of a MoOSTs knowledge platform (KP) that aim to provide complementary solutions for prognosis and enhanced decision-making from critically MoOSTs activities. 


\section{Limitations}

The scope of this work was limited to include analysis of data based on specific gaps identified from a prior SLR and questions asked in the interviews were directly relevant to the study aim of aligning practice with research. Another SLR might discover additional qualitative findings which will need to be elucidated in future empirical studies with the view of obtaining other practitioners' perspectives. In addition, the qualitative research method is often criticised for not usually being generalizable, because the conditions in which it is conducted can often not be replicated. However, this is not a hindrance or limitation to the research, but it is rather a feature that can be overcome by establishing common values of transparency during data collection, analysis and interpretation of results. It is the opinion of the authors that the research direction, discussions and outcomes from this study are very relevant in examining pertinent issues raised by research and practice in the study of knowledge management and experience transfer in MoOSTs. In addition, although a proposal for a MoOSTs KP has been recommended, the application and validation of such study is beyond the scope of this present study, but the aim is to show the relevance of the findings from this study and the crucial background it provides to achieving this important task. Moreover, this study should be treated as an ongoing work which could be further extended in future as the challenges in MoOSTs are quite dynamic.

Author Contributions: Conceptualization, L.O.I.-E. and A.Y.-K.; methodology, L.O.I.-E. and A.Y.-K.; validation, L.O.I.-E. and A.Y.-K.; formal data analysis, L.O.I.-E.; investigation, L.O.I.-E.; writing-original draft preparation, L.O.I.-E.; writing—review and editing, A.Y.-K.; supervision, A.Y.-K. All authors have read and agreed to the published version of the manuscript.

Funding: This research received no external funding.

Institutional Review Board Statement: The study was conducted according to the guidelines of the Declaration of Helsinki, and approved by the Ethics committee panel of Mechanical, Aerospace and Civil Engineering Department, University of Manchester, UK (Ref code: 2020-8009-13470) and date of approval 9 March 2020.

Informed Consent Statement: Informed consent was obtained from participants involved in the study.

Data Availability Statement: The data presented in this study are available on request from the corresponding author. Link to the survey can be found at Data I Qualtrics Experience Management (manchester.ac.uk; accessed on 14 December 2021).

Acknowledgments: L.O.I.-E. acknowledges receipt of a PhD scholarship from Petroleum Technology Development Fund (PTDF), Nigeria.

Conflicts of Interest: The authors declare no conflict of interest.

\section{Appendix A}

Question Guide for semi structured participants interview are available.

1. What are the major maintenance activities performed during MoOSTs?

2. How is the team formed, is it always the same core team or is it formed for every new MoOSTs project?

3. What are the main reasons for delays during MoOSTs?

4. What is the normal duration for MoOSTs Planning?

5. How long does the MoOSTs execution normally last?

6. What is the impact of delays on production costs? (Please asides from a summary, provide monetary figures).

7. What is the ICT utilized for planning, capturing knowledge during MoOSTs?

8. Is the communication process during MoOSTs paper based, electronic or a mix of both?

9. Do you organize meetings during MoOSTs to discuss ongoing projects? If yes, who participates at these meetings, how long do they last, where are they organized?

10. Do you review MoOSTs project? If yes before or after?

11. Do you write reports? If yes, who writes the report, and how is it stored? 
12. Could you give me any example of the issues that are treated in the reports or reviews?

13. What happens to the information that are generated from review meetings during MoOSTs?

14. Do you reference these reports in subsequent MoOSTs projects?

15. How are contractors briefed during MoOSTs, is there a representative?

16. How do you prioritize the knowledge you capture?

17. What happens to the information that are generated, are they saved? If yes, how are they saved and shared (paper based, online repository or real time, intranet, web based that is continually updated and made available immediately)?

18. What is the process for debriefing contractors?

19. Do you have any formalized approaches of learning from experience? I.e., is there a way experts are able to transfer their expertise across projects?

20. Can you give examples from your personal experience on how you learned new lessons?

21. In your opinion, what are the major barriers to knowledge management and learning from experience?

22. How do you think the barriers you have identified can be overcome, what measures do you envisage?

\section{References}

1. Lewandowski, M. Designing the business models for circular economy-Towards the conceptual framework. Sustainability 2016, 8, 43. [CrossRef]

2. $\quad$ Rizos, V.; Behrens, A.; Van Der Gaast, W.; Hofman, E.; Ioannou, A.; Kafyeke, T.; Flamos, A.; Rinaldi, R.; Papadelis, S.; Hirschnitz-Garbers, M.; et al. Implementation of Circular Economy Business Models by Small and Medium-Sized Enterprises (SMEs): Barriers and Enablers. Sustainability 2016, 8, 1212. [CrossRef]

3. Khasreen, M.M.; Banfill, P.F.G.; Menzies, G.F. Life-Cycle Assessment and the Environmental Impact of Buildings: A Review. Sustainability 2009, 1, 674-701. [CrossRef]

4. Kordab, M.; Raudeliūnienè, J.; Meidutè-Kavaliauskienė, I. Mediating Role of Knowledge Management in the Relationship between Organizational Learning and Sustainable Organizational Performance. Sustainability 2020, 12, 10061. [CrossRef]

5. Iheukwumere-Esotu, L.; Yunusa-Kaltungo, A. A Systematic Analysis of Research Based Evidences of Major Overhauls, Outages, Shutdowns, Turnarounds (MoOSTs) Management. In Mechanisms and Machine Science; Springer: Berlin/Heidelberg, Germany, 2021; Volume 105. [CrossRef]

6. Ambani, S.; Li, L.; Ni, J. Condition-Based Maintenance Decision-Making for Multiple Machine Systems. J. Manuf. Sci. Eng. 2009, 131, 031009. [CrossRef]

7. Zhang, Z.; Liu, G.; Jiang, Z.; Chen, Y. A Cloud-Based Framework for Lean Maintenance, Repair, and Overhaul of Complex Equipment. J. Manuf. Sci. Eng. 2015, 137, 040908. [CrossRef]

8. Shou, W.; Wang, J.; Wu, P.; Wang, X. Lean management framework for improving maintenance operation: Development and application in the oil and gas industry. Prod. Plan. Control 2021, 32, 585-602. [CrossRef]

9. Al-Turki, U.; Duffuaa, S.; Bendaya, M. Trends in turnaround maintenance planning: Literature review. J. Qual. Maint. Eng. 2019, 25, 253-271. [CrossRef]

10. Elwerfalli, A.; Khan, M.K.; Munive-Hernandez, J.E. Developing Turnaround Maintenance (TAM) Model to Optimise TAM Performance Based on the Critical Static Equipment (CSE) Of GAS Plants. Int. J. Ind. Eng. Oper. Manag. 2018, 1, 12-31.

11. Shou, W.; Wang, J.; Wu, P.; Wang, X. Value adding and non-value adding activities in turnaround maintenance process: Classification, validation, and benefits. Prod. Plan. Control 2019, 31, 60-77. [CrossRef]

12. Levitt, J. Managing Maintenance Shutdowns and Outages; [S.1.]. Industrial Pr Inc.: New York, NY, USA, 2004; 244p.

13. Duffuaa, S.O.; Hadidi, L.A. Using QFD to conduct performance assessment for turnaround maintenance in petrochemical infrastructure. J. Infrastruct. Syst. 2017, 23. [CrossRef]

14. Ashok, M.; Biswajit, S.; Jibitesh, M. Activity Crashing in Shutdown Maintenance Through Qualitative Assessment: A Case Study. Adv. Prod. Eng. Manag. 2011, 6, 239-248.

15. Utne, I.; Thuestad, L.; Finbak, K.; Thorstensen, T.A. Shutdown preparedness in oil and gas production. J. Qual. Maint. Eng. 2012, 18, 154-170. [CrossRef]

16. Egbunike, O.; Purvis, L.; Naim, M.M. A systematic review of research into the management of manufacturing capabilities. Prod. Plan. Control 2018, 29, 1349-1366. [CrossRef]

17. Raoufi, M.; Fayek, A.R. Process Improvement for Power Plant Turnaround Planning and Management. Int. J. Archit. Eng. Constr. 2014, 3, 168-181. [CrossRef]

18. Ruiz, P.P.; Foguem, B.K.; Grabot, B. Generating knowledge in maintenance from Experience Feedback. Knowl.-Based Syst. 2014, 68, 4-20. [CrossRef]

19. Kannan, K.; Arunachalam, N. A Digital Twin for Grinding Wheel: An Information Sharing Platform for Sustainable Grinding Process. J. Manuf. Sci. Eng. Trans. ASME 2019, 141. [CrossRef] 
20. Hadidi, L.A.; Khater, M.A. Loss prevention in turnaround maintenance projects by selecting contractors based on safety criteria using the analytic hierarchy process (AHP). J. Loss Prev. Process Ind. 2015, 34, 115-126. [CrossRef]

21. Mhlanga, M.Z.; Munapo, E.; Mavetera, N. Investigating causes of delays and cost escalation in project execution during turnarounds. Invest. Manag. Financ. Innov. 2016, 13, 334-348. [CrossRef]

22. Refaiy, M.; Labib, A. The effect of applying tacit knowledge on maintenance performance: An empirical study of the energy sector in the UK and Arab countries. Knowl. Manag. Res. Pract. 2009, 7, 277-288. [CrossRef]

23. Elwerfalli, A.; Khan, M.K.; Munive, J.E. A new methodology for improving TAM scheduling of oil and gas plants. Lect. Notes Eng. Comput. Sci. 2016, 2224, 807-812.

24. Bell, N. Mitigating the Loss of Critical Knowledge. Saf. Reliab. 2014, 34, 61-78. [CrossRef]

25. Costa, E.; Soares, A.L.; de Sousa, J.P. Information, knowledge and collaboration management in the internationalisation of SMEs: A systematic literature review. Int. J. Inf. Manag. 2016, 36, 557-569. [CrossRef]

26. Martínez, L.B.; Márquez, A.C.; Gunckel, P.V.; Andreani, A.A. The graphical analysis for maintenance management method: A quantitative graphical analysis to support maintenance management decision making. Qual. Reliab. Eng. Int. 2013, 29, 77-87. [CrossRef]

27. Eken, G.; Bilgin, G.; Dikmen, I.; Birgonul, M.T. A Lessons Learned Database Structure for Construction Companies. Procedia Eng. 2015, 123, 135-144. [CrossRef]

28. Suryani, R.; Munadi, K.; Idroes, R.; Sofyan, H. International Journal of Disaster Risk Reduction Knowledge management practices in disaster management: Systematic review. Int. J. Disaster Risk Reduct. 2020, 51, 101881. [CrossRef]

29. Almeida, F.; Miranda, E.; Falcão, J. Challenges and facilitators practices for knowledge management in large-scale scrum teams. J. Inf. Technol. Case Appl. Res. 2019, 21, 90-102. [CrossRef]

30. Asrar-ul-Haq, M.; Anwar, S. A systematic review of knowledge management and knowledge sharing: Trends, issues, and challenges. Cogent Bus. Manag. 2016, 3, 1127744. [CrossRef]

31. Ertl, B. Applying PMBOK to Shutdowns, Turnarounds and Outages; Republished with Permission (Plant Maintenance Resource Centre); Inter Plan System Inc.: Friendswood, TX, USA, 2005; Volume 20, p. 8.

32. Gururajan, V.; Fink, D. Attitudes towards knowledge transfer in an environment to perform. J. Knowl. Manag. 2010, 14, 828-840. [CrossRef]

33. Fang, S.C.; Yang, C.W.; Hsu, W.Y. Inter-organizational knowledge transfer: The perspective of knowledge governance. J. Knowl. Manag. 2013, 17, 943-957. [CrossRef]

34. Peng, H. Why and when do people hide knowledge? J. Knowl. Manag. 2013, 17, 398-415. [CrossRef]

35. Martelo-Landroguez, S.; Cepeda-Carrión, G. How knowledge management processes can create and capture value for firms? Knowl. Manag. Res. Pract. 2016, 14, 423-433. [CrossRef]

36. Zaim, H.; Muhammed, S.; Tarim, M. Relationship between knowledge management processes and performance: Critical role of knowledge utilization in organizations. Knowl. Manag. Res. Pract. 2019, 17, 24-38. [CrossRef]

37. Motamedi, A.; Hammad, A.; Asen, Y. Knowledge-assisted BIM-based visual analytics for failure root cause detection in facilities management. Autom. Constr. 2014, 43, 73-83. [CrossRef]

38. Schiuma, G.; Carlucci, D.; Lerro, A. Managing knowledge processes for value creation. VINE 2012, 42, 4-14. [CrossRef]

39. Durst, S.; Edvardsson, I.R. Knowledge management in SMEs: A literature review. J. Knowl. Manag. 2012, 16, 879-903. [CrossRef]

40. al Shraah, A.; Abu-Rumman, A.; al Madi, F.; Alhammad, F.A.F.; Aljboor, A.A. The impact of quality management practices on knowledge management processes: A study of a social security corporation in Jordan. TQM J. 2021. ahead-of-print. [CrossRef]

41. Wang, C.; Mao, Z.; Su, H.; Tian, Y. Knowledge identification in medium-sized enterprises under the context of quality improvement-an exploration in manufacturing companies in China. Prod. Plan. Control 2020, 7287, 415-440. [CrossRef]

42. Ansari, F. Knowledge Management 4.0: Theoretical and Practical Considerations in Cyber Physical Production Systems. IFAC-PapersOnLine 2019, 52, 1597-1602. [CrossRef]

43. Mitri, M. Applying tacit knowledge management techniques for performance assessment. Comput. Educ. 2003, 41, 173-189. [CrossRef]

44. Yazdi, M.; Soltanali, H. Knowledge acquisition development in failure diagnosis analysis as an interactive approach. Int. J. Interact. Des. Manuf. 2019, 13, 193-210. [CrossRef]

45. Smith, E.A. The role of tacit and explicit knowledge in the workplace. J. Knowl. Manag. 2001, 5, 311-321. [CrossRef]

46. Bevilacqua, M.; Ciarapica, F.E.; Giacchetta, G.; Marchetti, B. Development of an innovative criticality index for turnaround management in an oil refinery. Int. J. Product. Qual. Manag. 2012, 9, 519-544. [CrossRef]

47. Gera, R. Bridging the gap in knowledge transfer between academia and practitioners. Int. J. Educ. Manag. 2012, 26, 252-273. [CrossRef]

48. Kotlarsky, J.; Scarbrough, H.; Oshri, I. Coordinating expertise across knowledge Boundaries in offshore-Outsourcing projects: The role of codification 1. MIS Q. 2014, 38, 607-628. [CrossRef]

49. Iheukwumere-Esotu, L.O.; Kaltungo, A.Y. Assessment of barriers to knowledge and experience transfer in major maintenance activities. Energies 2020, 13, 1721. [CrossRef]

50. Cárdenas, L.J.A.; Ramírez, W.F.T.; Molano, J.I.R. Model for the Incorporation of Big Data in Knowledge Management Oriented to Industry 4.0. In Data Mining and Big Data; Springer International Publishing: Berlin/Heidelberg, Germany, 2018 ; pp. 683-693. 
51. Lee, J.; Ardakani, H.D.; Yang, S.; Bagheri, B. Industrial Big Data Analytics and Cyber-physical Systems for Future Maintenance \& Service Innovation. Procedia CIRP 2015, 38, 3-7. [CrossRef]

52. Yunusa-Kaltungo, A.; Sinha, J.K. Effective vibration-based condition monitoring (eVCM) of rotating machines. J. Qual. Maint. Eng. 2017, 23, 279-296. [CrossRef]

53. Jantunen, E.; Zurutuza, U.; Ferreira, L.L.; Varga, P. Optimising maintenance: What are the expectations for Cyber Physical Systems. In Proceedings of the 2016 3rd International Workshop on Emerging Ideas and Trends in Engineering of Cyber-Physical Systems (EITEC), Vienna, Austria, 11 April 2016; pp. 53-58. [CrossRef]

54. Ansari, F.; Glawar, R.; Nemeth, T. PriMa: A prescriptive maintenance model for cyber-physical production systems. Int. J. Comput. Integr. Manuf. 2019, 32, 482-503. [CrossRef]

55. Jazdi, N. Cyber physical systems in the context of Industry 4.0. In Proceedings of the 2014 IEEE International Conference on Automation, Quality and Testing, Robotics, Cluj-Napoca, Romania, 22-24 May 2014; pp. 14-16. [CrossRef]

56. Hernandez-de-Menendez, M.; Morales-Menendez, R.; Escobar, C.A.; McGovern, M. Competencies for Industry 4.0. Int. J. Interact. Des. Manuf. 2020, 14, 1511-1524. [CrossRef]

57. Yunusa-Kaltungo, A.; Labib, A. A hybrid of industrial maintenance decision making grids. Prod. Plan. Control 2021, 32, 397-414. [CrossRef]

58. Mezher, T.; Abdul-Malak, M.A.; Ghosn, I.; Ajam, M. Knowledge Management in Mechanical and Industrial Engineering Consulting: A Case Study. J. Manag. Eng. 2005, 21, 138-147. [CrossRef]

59. Grzybowska, K.; Łupicka, A. Key competencies for Industry 4.0. Econ. Manag. Innov. 2017, 1, 250-253. [CrossRef]

60. Ghazali, Z.; Shamim, A. Managing People in Plant Turnaround Maintenance: The Case of Three Malaysian Petrochemical Plants Platf. A J. Eng. Sci. Soc. 2014, 10, 42-57.

61. Bird, D.K. The use of questionnaires for acquiring information on public perception of natural hazards and risk mitigation-A review of current knowledge and practice. Nat. Hazards Earth Syst. Sci. 2009, 9, 1307-1325. [CrossRef]

62. Slattery, E.L.; Voelker, C.C.J.; Nussenbaum, B.; Rich, J.T.; Paniello, R.C.; Neely, J.G. A practical guide to surveys and questionnaires Otolaryngol.-Head Neck Surg. 2011, 144, 831-837. [CrossRef]

63. Kallio, H.; Pietilä, A.M.; Johnson, M.; Kangasniemi, M. Systematic methodological review: Developing a framework for a qualitative semi-structured interview guide. J. Adv. Nurs. 2016, 72, 2954-2965. [CrossRef]

64. Morton, R.L.; Devitt, J.; Howard, K.; Anderson, K.; Snelling, P.; Cass, A. Patient Views About Treatment of Stage 5 CKD: A Qualitative Analysis of Semistructured Interviews. Am. J. Kidney Dis. 2010, 55, 431-440. [CrossRef]

65. Krishnankutty, P.; Hwang, B.G.; Caldas, C.H.; Muralidharan, S.; de Oliveira, D.P. Assessing the implementation of best productivity practices in maintenance activities, shutdowns, and turnarounds of petrochemical plants. Sustainability 2019, 11, 1239. [CrossRef]

66. AlHamouri, K.; Caldas, C.H.; Hwang, B.-G.; Krishnankutty, P.; de Oliveira, D.P. Utilization of workface planning for the execution of maintenance activities, shutdowns and turnarounds in petrochemical facilities-A case study. Int. J. Constr. Manag. 2021, 21, 1115-1129. [CrossRef]

67. Hameed, A.; Khan, F. A framework to estimate the risk-based shutdown interval for a processing plant. J. Loss Prev. Process Ind. 2014, 32, 18-29. [CrossRef]

68. Amendola, L.; Depool, T.; Artacho, M.A. Identification of the critical phases and decision-making criteria for the shutdown of chemical processing plants case studies: South America, Spain and Portugal. Int. J. Ind. Eng. Theory Appl. Pract. 2010, 17, 200-211.

69. Al-Turki, U.M.; Duffuaa, S.O.; Ben-Daya, M.A. A holistic system approach for turnaround performance management. Maint. Perform. Meas. Manag. 2013. [CrossRef]

70. Muganyi, P.; Mbohwa, C. Shutdown Maintenance Drivers under an Integrated and Business Focused Maintenance System. In Proceedings of the International Conference on Industrial, Manufacturing, Automation and Mechanical Engineering (IMAME), Johannesburg, South Africa, 27-28 November 2013.

71. Duffuaa, S.O.; Al-Turki, U.M.; Daya, M.B. Status of Integrated Turnaround Maintenance. In Proceedings of the 2019 Industrial \& Systems Engineering Conference (ISEC), Jeddah, Saudi Arabia, 19-20 January 2019; pp. 1-4. [CrossRef]

72. Pearson, N.; Naylor, P.-J.; Ashe, M.C.; Fernandez, M.; Yoong, S.L.; Wolfenden, L. Guidance for conducting feasibility and pilot studies for implementation trials. Pilot Feasibility Stud. 2020, 6, 167. [CrossRef] [PubMed]

73. Blatch-Jones, A.J.; Pek, W.; Kirkpatrick, E.; Ashton-Key, M. Role of feasibility and pilot studies in randomised controlled trials: A cross-sectional study. BMJ Open 2018, 8, e022233. [CrossRef] [PubMed]

74. Runeson, P.; Höst, M. Guidelines for conducting and reporting case study research in software engineering. Empir. Softw. Eng. 2009, 14, 131-164. [CrossRef]

75. Campbell, S.; Greenwood, M.; Prior, S.; Shearer, T.; Walkem, K.; Young, S.; Bywaters, D.; Walker, K. Purposive sampling: Complex or simple? Research case examples. J. Res. Nurs. 2020, 25, 652-661. [CrossRef] [PubMed]

76. Ahmad, A.; Li, K.; Feng, C.; Asim, S.M.; Yousif, A.; Ge, S. An Empirical Study of Investigating Mobile Applications Development Challenges. IEEE Access 2018, 6, 17711-17728. [CrossRef]

77. Ghazali, Z.; Halib, M. The Organization of Plant Turnaround Maintenance in Process-Based Industries: Analytical Framework and Generic Processes. J. Int. Bus. Manag. Res. 2011, 2, 30-43.

78. Mazumder, L.K.; Mubashar, S. A study on plant shut down process and its impact on time and cost. Int. J. Res. IT Manag. 2016, 10, 1-5. 
79. Rigb, P.C.; Zhu, Y.C.; Donadell, S.M.; Mockus, A. Quantifying and mitigating turnover-induced knowledge loss: Case studies of chrome and a project at avaya. In Proceedings of the 2016 IEEE/ACM 38th International Conference on Software Engineering (ICSE), Austin, TX, USA, 14-22 May 2016; pp. 1006-1016. [CrossRef]

80. Al Shayea, A.M. Best period of time for performing shutdown maintenance. Int. J. Collab. Enterp. 2011, 2, 275. [CrossRef]

81. Ghazali, Z.; Halib, M.; Nordin, S.M.; Ghazali, M.C. Rusty Bolts and Broken Valves: A Study on The Plant Technology, Size, And Organizational Structure of Plant Turnaround Maintenance in Malaysian Process-Based Industries Industries. Int. Rev. 2009, 5, 239-256.

82. Hong, Q.N.; Pluye, P.; Bujold, M.; Wassef, M. Convergent and sequential synthesis designs: Implications for conducting and reporting systematic reviews of qualitative and quantitative evidence. Syst. Rev. 2017, 6, 61. [CrossRef]

83. Castleberry, A.; Nolen, A. Thematic analysis of qualitative research data: Is it as easy as it sounds? Curr. Pharm. Teach. Learn. 2018, 10, 807-815. [CrossRef]

84. Sutton, J.; Austin, Z. Qualitative Research: Data Collection, Analysis, and Management. Can. J. Hosp. Pharm. 2015, 68, 226-231. [CrossRef]

85. Maindonald, J.H. Qualitative Research from Start to Finish by Robert K. Yin. Int. Stat. Rev. 2011. [CrossRef]

86. Tan, H.C.; Carrillo, P.M.; Anumba, C.J.; Bouchlaghem, N.D.; Kamara, J.M.; Udeaja, C.E. Development of a Methodology for Live Capture and Reuse of Project Knowledge in Construction. J. Manag. Eng. 2007, 23, 18-26. [CrossRef]

87. Hari, S.; Egbu, C.; Kumar, B. A knowledge capture awareness tool: An empirical study on small and medium enterprises in the construction industry. Eng. Constr. Archit. Manag. 2005, 12, 533-567. [CrossRef]

88. Riege, A. Three-dozen knowledge-sharing barriers managers must consider. J. Knowl. Manag. 2005, 9, 18-35. [CrossRef]

89. Iheukwumere-Esotu, L.O.; Yunusa-Kaltungo, A. Knowledge criticality assessment and codification framework for major maintenance activities: A case study of cement rotary kiln plant. Sustainability 2021, 13, 4619. [CrossRef]

90. Appoh, F.; Yunusa-Kaltungo, A.; Sinha, J.K.; Kidd, M. Practical Demonstration of a Hybrid Model for Optimising the Reliability, Risk, and Maintenance of Rolling Stock Subsystem. Urban Rail Transit 2021, 7, 139-157. [CrossRef] 